\title{
Job-Finding and Job-Losing: A Comprehensive Model of Heterogeneous Individual Labor-Market Dynamics
}

\author{
Robert E. Hall \\ Hoover Institution and Department of Economics \\ Stanford University \\ Marianna Kudlyak \\ Federal Reserve Bank of San Francisco \\ January 2020 \\ Working Paper 2019-05 \\ https://www.frbsf.org/economic-research/publications/working-papers/2019/05/ \\ Hall, Robert E., Marianna Kudlyak. 2020. “Job-Finding and Job-Losing: A \\ Comprehensive Model of Heterogeneous Individual Labor-Market Dynamics,” Federal \\ Reserve Bank of San Francisco Working Paper 2019-05. \\ The views in this paper are solely the responsibility of the authors and should not be interpreted as \\ reflecting the views of the Federal Reserve Bank of San Francisco or the Board of Governors of
}

\section{Suggested citation:}

https://doi.org/10.24148/wp2019-05 the Federal Reserve System. 


\title{
Job-Finding and Job-Losing: A Comprehensive Model of Heterogeneous Individual Labor-Market Dynamics *
}

\author{
Robert E. Hall \\ Hoover Institution and Department of Economics \\ Stanford University \\ rehall@stanford.edu; stanford.edu/ rehall \\ Marianna Kudlyak \\ Federal Reserve Bank of San Francisco \\ marianna.kudlyak@sf.frb.org; sites.google.com/site/mariannakudlyak/
}

January 14, 2020

\begin{abstract}
We study the paths over time that individuals follow in the labor market, as revealed in the monthly Current Population Survey. Some people face much higher flow values from work than in a non-market activity; if they lose a job, they find another soon. Others have close to equal flow values and tend to circle through jobs, search, and nonmarket activities. And yet others have flow values for non-market activities that are higher than those in the market, and do not work. We develop a model that identifies and quantifies heterogeneity in dynamic individual behavior. Our model provides a bridge between research on monthly transition rates in the tradition of Blanchard and Diamond (1990) and research on economic dynamics in the tradition of Mortensen and Pissarides (1994). Our estimates discern 5 distinct types. Most unemployment comes from just two of those types. Low employment types frequently circle among unemployment, short-term jobs, and being out of the labor market. Short-term jobs play a role in the job-finding process related to the role of unemployment. These are stop-gap jobs for high-employment types and a part of circling for low-employment types. Because of their high job-finding rates, and despite their low flow values of nonwork relative to work, the volatility of the future lifetime value that high-employment types derive from work and non-work is lower than for low-employment types.
\end{abstract}

*Hall's research was supported by the Hoover Institution. Any opinions expressed are those of the authors and do not reflect those of the Federal Reserve Bank of San Francisco or the Federal Reserve System. We thank Roc Armenter, Mark Bils, John Cochrane, Steve Davis, Hank Farber, Sebastian Graves, Fatih Guvenen, Jim Hamilton, Ken Judd, Ioannis Kospentaris, Pablo Kurlat, Jeremy Lise, Davide Melcangi, Guido Menzio, Giuseppe Moscarini, Toshihiko Mukoyama, Andriy Norets, Elena Pastorino, Richard Rogerson, Robert Shimer, and Wilbert van den Klauuw, and participants in conferences and seminars, for helpful comments. JEL E24 J63 J64 
We study the economics of personal labor-market dynamics. Some working-age people face flow values from a job that considerably exceed the flow value of any available non-market activity. If they lose a job, they tend to find another fairly soon through intensive search. Other people have close to equal flow values and tend to circle through jobs, unemployment, and non-market activities. And some people have generally higher values in non-market activities and take jobs infrequently or not at all.

The objective of our research is to develop and estimate a model of the movement of individuals among (1) remaining out of the labor market, (2) unemployment, and (3) employment. The model provides a bridge between research on monthly transition rates in the tradition of Blanchard and Diamond (1990) and research on economic dynamics in the tradition of Mortensen and Pissarides (1994). The model takes account of the heterogeneity of flow values and the resulting heterogeneity in the paths individuals take among the three activities. We capture heterogeneity at two levels, first between women and men, and then with a modeling technique that finds a finite number of types for women and for men, based on their activity paths.

For each type, we estimate a dynamic program describing economic decisions about participation, unemployment, and job retention. The program contains hidden states to deal with longer-term time dependence among the observed activities that cannot be captured in a model that focuses on month-to-month transitions in the observed activities.

We match the statistical behavior of individuals at quite a general level, in terms of the probability distribution of the paths of individuals over time as they move among the three observed activities. Our model generates such a distribution, based on the model's parameters. We form the frequency distribution of paths in survey data. Then we find the parameter values that best match the model's distribution to the frequency distribution of the data. Our estimated model discerns 5 types among women and another 5 among men, for a total of 10 estimated types.

We find that heterogeneity in the population is substantial. A fairly large fraction of working-age people tend to remain employed for long spells. A small fraction remain out of the labor force. Approximately one person out of three tends to move among three activities - unemployment, time out of the labor force, and employment. Among the mover population, there are those who spend a significant fraction of their time employed, that is, high-employment types, and those who spend a significant fraction of their time unemployed or out of the labor force, that is, low-employment types. Most unemployment comes from a small segment of the mover population.

Short-term jobs occur frequently and are partly a substitute for unemployment - they are a natural extension of the search process. Short-term jobs often precede stable employment 
and serve as stepping-stone jobs for high-employment types. Frequent month-to-month circling among unemployment, out of the labor force, and short jobs characterizes lowemployment types.

We find that the high-employment types typically have a much lower flow value from non-work relative to the flow value from work, as compared to the low-employment types. However, if they lose a job, they find another fairly soon through intensive search. In contrast, the flow values from non-work and from work of the low-employment types are more similar. But if a low-employment type loses a stable job, the probability of finding another is low. Because of the high-employment type's high job finding rates, and despite their low flow values of non-work, the volatility of the high-employment type's Bellman values arising from transitions between non-work and work is lower than for low-employment types. In this sense, the life of the low-employment types is riskier.

We use data from the Current Population Survey on activity paths. The CPS covers a 16-month period of a respondent's labor-market experiences. It is well suited for studying dynamic issues over that time span, but not to studying life-cycle issues, where long panel data with much less frequent interviews are better suited. The CPS better serves our objectives than would quarterly and annual administrative data on earnings, because the CPS records key monthly information about labor-market activities for a large representative cross-section of the population.

The distribution of activities over the 8 months recorded in the CPS offers a vastly richer description of labor-market dynamic outcomes than the one-month transition matrixes that have been studied historically. A recent literature has explored improvements over the traditional first-order Markov model of the labor-force transitions reported in the CPS. Kudlyak and Lange (2018) find that employment in the months immediately preceding a given month dramatically raises the conditional probability of a move from out of the labor force to employment in that month. This finding implies that studying transitions in a month without considering earlier months, is mistaken - the conditioning information from employment in earlier months has substantial influence.

Hall and Schulhofer-Wohl (2018), following Krueger, Cramer and Cho (2014), look at the issue in the reverse way, by considering more than just one month ahead, conditional on the current month. This approach generates different longer-run transition rates than would occur from repeated application of one-month transition probabilities.

This paper is entirely about personal dynamics and not about aggregate dynamics. We estimate the model with data from a quiescent period of moderate unemployment. Although individuals experience dynamic change, the sum across millions of them changes very little 
each month. In future work, we plan to use the same tools to study aggregate changes, with emphasis on the explosion of unemployment following the financial crisis in late 2008.

Further, the paper is not offered as a contribution to the long-standing literature on decomposing observed duration dependence into components arising from heterogeneity and true duration effects. Our model includes one important source of true duration dependence through its distinction between short-term and longer-term jobs.

We distinguish five types in the population. Each type has its own economic model and vector of estimated parameters. We also estimate the fraction of the population that each type describes. The probability distribution of the overall model is the weighted average of the distributions of the types - it is a probability mixture, in the terminology of the statistical literature on heterogeneity.

We estimate the parameters of our model using the 16-month time span of the individual records in the CPS. We use the model to interpolate behavior during the 8 months in the middle of those records when respondents' activities are not reported, and to extrapolate beyond the end of the 16 months for another year or two. We do not regard our model as describing behavior over longer time spans. We do not consider slower-moving changes in behavior that occur over lower frequencies, such as from decade to decade. We do not describe movements from one type to another. As noted above, we do not consider changes that arise from the business cycle. Accordingly, our claim to building a bridge to the DMP model refers to its personal dynamic program and not to the labor-market equilibrium of the DMP model.

We do believe that the modeling techniques developed in this paper could be applied to longer time spans, by using different panel surveys, such as the SIPP, the PSID or the NLSY. Morchio (2019) is a pioneering effort in that direction.

Reader's guide: Section 1 applies the modeling tools of the DMP tradition to the issues considered in this paper. It shows how a model for a particular type implies transition probabilities among hidden personal states. Section 2 describes our model of heterogeneity in terms of five types of individuals in the populations of women and men. Section 3 shows how we compile data on activity paths from the CPS into a set of moments that are the targets for estimation. Section 4 lays out our procedure for estimating the transition probabilities for the types and fraction of the population that each type accounts for. Sections 5 and 6 put the dynamic model through its paces, focusing on the implications for job-finding following

an unemployment shock and related topics relating to labor-market activities. Sections 7 and 8 return to the role of the non-market flow value, unemployment flow value, and wage, in distinguishing the types and their chosen activities. We pull together the statistical and 
economic findings to construct portraits of the experiences of the women and men of each of the five types.

\section{Model for a Single Type}

In the dynamic program for a type, random events govern the individual's choices. Each month, the individual chooses from among a set of available options, picking the one with the highest Bellman value. The individual choices determine the transitions among individual's labor market situations, which in the model are captured by the individual's labor market state and activity. The transition probability matrix is an economic object, not a predetermined set of probabilities.

Time is discrete at the monthly frequency. Utility is linear in consumption. Individuals discount the next month's outcomes at the rate $\frac{1}{1+r}$. They maximize the present value of utility.

The discussion in this section applies to a single type. All of the parameters in the model depend on the type, $\theta$. To simplify the notation, we do not include the subscript $\theta$ in this section of the paper.

Each month, an individual's personal situation is described by two variables: state and activity. A state, designated $s$, describes the labor-market state of an individual, inherited from random events that occurred in earlier months channeled through the individual's choices. Each state is characterized by a set of possible activities. For example, the employment activity is available in some states but not in others. An activity, designated $a$, describes the individual's choice from the set of possible activities available when the individual is in state $s$. The outcome of that choice, a vector of elements $a_{s}$, is the individual's policy function, in the vocabulary of dynamic programming.

An individual's state $s$ takes on four values. States 1 and 2 apply to individuals who are not starting the month in a job. We call $s=1$ inactive non-work and call $s=2$ active nonwork. In state 2 , the individual is under the influence of a possibly transient force favoring taking steps to find a job. From the model's perspective, the main distinction between the two states is that the probability of finding a job from non-employment is higher in state 2 than in state 1 . Our concept of activated non-work captures some of the behavior recorded in the CPS among people close to the margin of participation in the labor market. For example, those recorded as out of the labor force but desiring to work and available to work are much more likely to find work in the ensuing month than those who are not available (see Hall and Schulhofer-Wohl (2018)). Becoming available through some random change in personal or family circumstances is part of our concept of activation. 
States 3 and 4 apply to people with jobs. If the job is a poor match that could only serve as an interim job, the individual is in state 3, called short-term job. If the job is a good match and likely to be durable, the individual is in state 4 , which we call longer-term job. The individual knows which state he is in; there is no learning. From the model's perspective, the main distinction between the two kinds of job is that probability of separation from the job is higher in state 3 than in state 4 . We chose two kinds of employment states so that our model can generate the decline of the separation rate with tenure observed in the data. We elaborate on this point later in the paper.

Individuals in the non-work states, 1 and 2, choose between remaining out of the labor force or being unemployed. Unemployment involves active job search. We have in mind the distinction made in the CPS, where a non-employed person who engaged in active search in the four weeks before the survey is classified as unemployed, while those who might have some interest in finding a job but who were not active during those weeks are counted as out of the labor force. We define activity $a$ to be $\mathrm{N}$ if unemployment is not chosen and $\mathrm{U}$ if it is. The only possible activity in work states, 3 and 4 , is employment, denoted E.

During the month, individuals experience random events that may result in transitions to other states and therefore open possibilities of other activities. The probability of arrival of these random events depends on the individual's current state and activity. Some events open up favorable opportunities and some are adverse shocks. The choices open to the individual are as follows: Whenever an individual is presented with an opportunity to move to a higher state, the individual can always choose any of the lower-numbered states. Whenever a shock forces a move to a lower state, the individual needs to move to that state or can choose any of the even lower states. Thus individuals always keep in mind that exiting the labor force or quitting a job may be the best available alternative.

We formalize this process as follows: Each month, an individual in state $s$ and activity $a$ draws $j \in[1,2,3,4]$ from a distribution of arrival probabilities $\tau_{a, s, s^{\prime}}$ defined across activity $a$ and current state $s$ and the four possible future states $s^{\prime}$. If $j$ exceeds $s$, the individual has received an opportunity, and if $j$ is less than $s$, the individual has suffered a shock. After learning $j$, the individual chooses future state $s^{\prime}$ from $\{1, \ldots, j\}$. Because the only activity in states 3 and 4 is employment, we drop E from the notation for probabilities for arrivals originating in those states. Table 1 shows the probability distribution of the random influence $j$ conditional on $s$ and $a$.

In the data, we observe an individual's activity but not the state. The states are partially hidden because when an individual is not employed we know that she is in $s=1$ or $s=2$, while an employed individual is in $s=3$ or $s=4$. An unemployed individual or one out of 


\begin{tabular}{cc|cccc}
\hline \hline $\begin{array}{c}\text { Originating } \\
\text { state }\end{array}$ & Activity & \multicolumn{4}{|c}{ Destination state } \\
\hline 1 & $\mathrm{~N}$ & $\tau_{\mathrm{N}, 1,1}$ & $\tau_{\mathrm{N}, 1,2}$ & $\tau_{\mathrm{N}, 1,3}$ & $\tau_{\mathrm{N}, 1,4}$ \\
1 & $\mathrm{U}$ & $\tau_{\mathrm{U}, 1,1}$ & $\tau_{\mathrm{U}, 1,2}$ & $\tau_{\mathrm{U}, 1,3}$ & $\tau_{\mathrm{U}, 1,4}$ \\
2 & $\mathrm{~N}$ & $\tau_{\mathrm{N}, 2,1}$ & $\tau_{\mathrm{N}, 2,2}$ & $\tau_{\mathrm{N}, 2,3}$ & $\tau_{\mathrm{N}, 2,4}$ \\
2 & $\mathrm{U}$ & $\tau_{\mathrm{U}, 2,1}$ & $\tau_{\mathrm{U}, 2,2}$ & $\tau_{\mathrm{U}, 2,3}$ & $\tau_{\mathrm{U}, 2,4}$ \\
3 & $\mathrm{E}$ & $\tau_{3,1}$ & $\tau_{3,2}$ & $\tau_{3,3}$ & $\tau_{3,4}$ \\
4 & $\mathrm{E}$ & $\tau_{4,1}$ & $\tau_{4,2}$ & $\tau_{4,3}$ & $\tau_{4,4}$ \\
\hline \hline
\end{tabular}

Table 1: Arrival Probabilities of Opportunities and Shocks

the labor force may be in $s=1$ or $s=2$. The individual always knows his state - we do not model learning.

Finally, individuals receive flow values based on their states and activity choices. The flow values are $z$ for $\mathrm{N}$ in states 1 and $2, b$ for $\mathrm{U}$ in states 1 and $2, w_{3}$ in state 3 , and $w_{4}$ in state 4 . We normalize $w_{4}$ to 1 .

We now describe the workings of the model in terms of its Bellman values:

- $N_{1}$ : Value of remaining out of the labor force in state 1

- $U_{1}$ : Value of being unemployed in state 1

- $N_{2}$ : Value of remaining out of the labor force in state 2

- $U_{2}$ : Value of being unemployed in state 2

- $E_{3}$ : Value of holding a short-term job, state 3

- $E_{4}$ : Value of holding a longer-term job, state 4

We describe the process in some detail for state $s=1$, not activated, and activity $a=\mathrm{N}$, out of the labor force. The Bellman equation for the value $N_{1}$ is

$$
\begin{array}{r}
N_{1}=z+\frac{1}{1+r}\left(\tau_{\mathrm{N}, 1,1} \max \left(N_{1}, U_{1}\right)+\tau_{\mathrm{N}, 1,2} \max \left(N_{1}, U_{1}, N_{2}, U_{2}\right)\right. \\
\left.+\tau_{\mathrm{N}, 1,3} \max \left(N_{1}, U_{1}, N_{2}, U_{2}, E_{3}\right)+\tau_{\mathrm{N}, 1,4} \max \left(N_{1}, U_{1}, N_{2}, U_{2}, E_{3}, E_{4}\right)\right) .
\end{array}
$$

The individual receives a flow value $z$. The probability of $j=1$ from this starting point is $\tau_{\mathrm{N}, 1,1}$. In that case, the individual chooses between $\mathrm{N}$ and $\mathrm{U}$ based on their values $N_{1}$ and $U_{1}$. The probability of $j=2$ is $\tau_{\mathrm{N}, 1,2}$. In this case, the individual has access to all four of the non-working alternatives, with values $N_{1}, U_{1}, N_{2}$, and $U_{2}$. The probability of $j=3$ is $\tau_{\mathrm{N}, 1,3}$, and, with this draw, the individual decides among five choices - the four non-work 
alternatives and short-term employment, with value $E_{3}$. Finally, with probability $\tau_{\mathrm{N}, 1,4}$, the individual draws $j=4$ and has a free choice among all 6 of the choices, including the leap from inactive out-of-the-labor-force directly to longer-term employment.

The other Bellman equations are:

For the unemployed with $s=1$,

$$
\begin{array}{r}
U_{1}=b+\frac{1}{1+r}\left(\tau_{\mathrm{U}, 1,1} \max \left(N_{1}, U_{1}\right)+\tau_{\mathrm{U}, 1,2} \max \left(N_{1}, U_{1}, N_{2}, U_{2}\right)\right. \\
\left.+\tau_{\mathrm{U}, 1,3} \max \left(N_{1}, U_{1}, N_{2}, U_{2}, E_{3}\right)+\tau_{\mathrm{U}, 1,4} \max \left(N_{1}, U_{1}, N_{2}, U_{2}, E_{3}, E_{4}\right)\right) .
\end{array}
$$

For those out of the labor force with $s=2$,

$$
\begin{array}{r}
N_{2}=z+\frac{1}{1+r}\left(\tau_{\mathrm{N}, 2,1} \max \left(N_{1}, U_{1}\right)+\tau_{\mathrm{N}, 2,2} \max \left(N_{1}, U_{1}, N_{2}, U_{2}\right)\right. \\
\left.+\tau_{\mathrm{N}, 2,3} \max \left(N_{1}, U_{1}, N_{2}, U_{2}, E_{3}\right)+\tau_{\mathrm{N}, 2,4} \max \left(N_{1}, U_{1}, N_{2}, U_{2}, E_{3}, E_{4}\right)\right),
\end{array}
$$

For the unemployed with $s=2$,

$$
\begin{array}{r}
U_{2}=b+\frac{1}{1+r}\left(\tau_{\mathrm{U}, 2,1} \max \left(N_{1}, U_{1}\right)+\tau_{\mathrm{U}, 2,2} \max \left(N_{1}, U_{1}, N_{2}, U_{2}\right)\right. \\
\left.+\tau_{\mathrm{U}, 2,3} \max \left(N_{1}, U_{1}, N_{2}, U_{2}, E_{3}\right)+\tau_{\mathrm{U}, 2,4} \max \left(N_{1}, U_{1}, N_{2}, U_{2}, E_{3}, E_{4}\right)\right),
\end{array}
$$

For workers holding a short-term job with $s=3$,

$$
\begin{array}{r}
E_{3}=w_{3}+\frac{1}{1+r}\left(\tau_{3,1} \max \left(N_{1}, U_{1}\right)+\tau_{3,2} \max \left(N_{1}, U_{1}, N_{2}, U_{2}\right)\right] \\
\left.+\tau_{3,3} \max \left(N_{1}, U_{1}, N_{2}, U_{2}, E_{3}\right)+\tau_{3,4} \max \left(N_{1}, U_{1}, N_{2}, U_{2}, E_{3}, E_{4}\right)\right),
\end{array}
$$

For workers holding a longer-term job with $s=4$,

$$
\begin{array}{r}
E_{4}=w_{4}+\frac{1}{1+r}\left(\tau_{4,1} \max \left(N_{1}, U_{1}\right)+\tau_{4,2} \max \left(N_{1}, U_{1}, N_{2}, U_{2}\right)\right. \\
\left.+\tau_{4,3} \max \left(N_{1}, U_{1}, N_{2}, U_{2}, E_{3}\right)+\tau_{4,4} \max \left(N_{1}, U_{1}, N_{2}, U_{2}, E_{3}, E_{4}\right)\right) .
\end{array}
$$

Notice that the model does not start with a given transition process for the states. If an opportunity arrives to transition to a state, the individual has a choice about which state to transition to. The transition process emerges from the random events described in the model and the choices made by the individual. The model employs the 6 Bellman values to describe those choices. Each choice appears as a max function applied to the Bellman values of the alternatives available to the individual at a decision point.

\subsection{The transition matrix among states}

The model for a type determines the transition matrix among states based on the choices made by the individual based on the Bellman values. The driving forces of transitions are 
the random arrival of state- and activity-specific opportunities and shocks, $j$. The Bellman system can be solved for the Bellman values once-and-for-all, using linear programming.

There are four distinct max functions in the Bellman system: $\max \left(N_{1}, U_{1}\right), \max \left(N_{1}, U_{1}\right.$, $\left.N_{2}, U_{2}\right), \max \left(N_{1}, U_{1}, N_{2}, U_{2}, E_{3}\right.$, and $\max \left(N_{1}, U_{1}, N_{2}, U_{2}, E_{3}, E_{4}\right)$. The four functions have a recursive structure:

$$
\begin{gathered}
V_{1}=\max \left(N_{1}, U_{1}\right) \\
V_{2}=\max \left(V_{1}, N_{2}, U_{2}\right) \\
V_{3}=\max \left(V_{2}, E_{3}\right) \\
V_{4}=\max \left(V_{3}, E_{4}\right)
\end{gathered}
$$

The ranking of the Bellman values in equation (7) through equation (10) dictates all of the choices in the Bellman system - it ordains the choice with the highest Bellman value in each of the max functions that appear in the system. For each ranking, the model has a first-order Markov structure in the states.

The model maps many combinations of the model's parameters into the same ranking of the Bellman values, and thus to the same set of choices. The parameters of a type comprise the flow-value parameters $\left(z, b\right.$, and $\left.w_{3}\right)$ and arrival probabilities $\tau_{a, s, s^{\prime}}$. The set of parameters that map into a given Bellman ranking defines a partition of the parameter space. Within a partition, the choice of the state and activity at each decision node is already determined, so the transition rates in a partition are functions of only the arrival probabilities of shocks and opportunities. If we know the ranking, we can estimate the arrival probabilities parameters from observed transitions in the data and infer conclusions about the flow values that are consistent with the partition.

\subsection{Partitions defined by ranking of Bellman values}

Table 2 shows the $2 \times 3 \times 2 \times 2=24$ distinct rankings of the Bellman values in equation (7) through equation (10): 2 choices for $V_{1}, V_{3}$, and $V_{4}$ and 3 choices for $V_{2}$. Each combination of $V_{1}, V_{2}, V_{3}$, and $V_{4}$ defines a partition of the parameters of a type's dynamic program. There are four categories of the partitions. In the first category, at the upper left of the table, individuals are observed in all three activities and have positive probabilities of visiting all four states. In the second category, individuals are observed only out of the labor force. In the third category, individuals are observed in all three activities but visit only one employment 


\begin{tabular}{|c|c|c|c|c|c|c|c|c|c|}
\hline \multirow{2}{*}{$\begin{array}{c}\text { Partition } \\
\text { number }\end{array}$} & \multicolumn{4}{|c|}{ Random draw, $j$} & \multirow{2}{*}{$\begin{array}{c}\text { Partition } \\
\text { number }\end{array}$} & \multicolumn{4}{|c|}{ Random draw, $j$} \\
\hline & 1 & 2 & 3 & 4 & & 1 & 2 & 3 & 4 \\
\hline \multicolumn{5}{|c|}{ All 3 activities and 4 states } & \multicolumn{5}{|c|}{ Zero ergodic probability for one or more activities } \\
\hline 1 & $N_{1}$ & $U_{2}$ & $E_{3}$ & $E_{4}$ & 11 & $U_{1}$ & $U_{1}$ & $U_{1}$ & $U_{1}$ \\
\hline 2 & $U_{1}$ & $N_{2}$ & $E_{3}$ & $E_{4}$ & 12 & $U_{1}$ & $N_{2}$ & $N_{2}$ & $\mathrm{~N}_{2}$ \\
\hline \multicolumn{5}{|c|}{ Only $\mathrm{N}$ activity } & 13 & $N_{1}$ & $U_{2}$ & $U_{2}$ & $U_{2}$ \\
\hline 3 & $N_{1}$ & $N_{1}$ & $N_{1}$ & $N_{1}$ & 14 & $U_{1}$ & $U_{2}$ & $U_{2}$ & $U_{2}$ \\
\hline 4 & $N_{1}$ & $N_{2}$ & $N_{2}$ & $N_{2}$ & 15 & $N_{1}$ & $N_{1}$ & $E_{3}$ & $E_{3}$ \\
\hline \multicolumn{5}{|c|}{ Zero ergodic probability for $E_{3}$ or $E_{4}$} & 16 & $U_{1}$ & $U_{1}$ & $E_{3}$ & $E_{3}$ \\
\hline 5 & $U_{1}$ & $N_{2}$ & $E_{3}$ & $E_{3}$ & 17 & $N_{1}$ & $N_{2}$ & $E_{3}$ & $E_{3}$ \\
\hline 6 & $N_{1}$ & $U_{2}$ & $E_{3}$ & $E_{3}$ & 18 & $N_{1}$ & $N_{1}$ & $N_{1}$ & $E_{4}$ \\
\hline 7 & $U_{1}$ & $U_{2}$ & $E_{3}$ & $E_{3}$ & 19 & $U_{1}$ & $U_{1}$ & $U_{1}$ & $E_{4}$ \\
\hline 8 & $U_{1}$ & $\mathrm{~N}_{2}$ & $N_{2}$ & $E_{4}$ & 20 & $U_{1}$ & $U_{2}$ & $U_{2}$ & $E_{4}$ \\
\hline 9 & $U_{1}$ & $N_{2}$ & $N_{2}$ & $E_{4}$ & 21 & $N_{1}$ & $N_{1}$ & $E_{3}$ & $E_{4}$ \\
\hline \multirow[t]{3}{*}{10} & $N_{1}$ & $U_{2}$ & $U_{2}$ & $E_{4}$ & 22 & $U_{1}$ & $U_{2}$ & $E_{3}$ & $E_{4}$ \\
\hline & & & & & 23 & $N_{1}$ & $\mathrm{~N}_{2}$ & $E_{3}$ & $E_{4}$ \\
\hline & & & & & 24 & $U_{1}$ & $U_{2}$ & $E_{3}$ & $E_{4}$ \\
\hline
\end{tabular}

Table 2: All Possible Rankings of the Bellman Values

state - either short- or longer-term job. In the forth category, in the right-hand panel of the table, individuals are observed in two or fewer activities (except only N).

There are two partitions in the first category, which allows all 3 activities and 4 states, including two kinds of jobs. These partitions admit the most general transition matrix across states, without restricting some transitions to zero as other partitions do. We thus estimate a transition matrix of a type under the assumption that a type is in one of these two partitions. We later statistically test the elements of the estimated matrixes and confirm the choice of the partitions. Section 7 goes into details about the partitions.

We call these two partitions mover partitions because they generate paths that have positive probabilities for all of the states and activities. In mover partition 1 the individual chooses to be out of the labor force in state 1 , unemployed in state 2 , holding a short-term job in state 3 , and holding a longer-term job in state 4 . Working through equation (7) to equation (10) for these choices, we have:

$$
\begin{gathered}
N_{1}=\max \left(N_{1}, U_{1}\right) \\
U_{2}=\max \left(N_{1}, N_{2}, U_{2}\right)
\end{gathered}
$$




$$
\begin{aligned}
& E_{3}=\max \left(U_{2}, E_{3}\right) \\
& E_{4}=\max \left(E_{3}, E_{4}\right) .
\end{aligned}
$$

Compactly,

$$
E_{4} \geq E_{3} \geq U_{2} \geq N_{1} \geq U_{1} \text { and } U_{2} \geq N_{2} .
$$

Mover partition 2 is similar to 1 except that the individual chooses unemployment in state 1 and is out of the labor force in state 2. Its compact expression is

$$
E_{4} \geq E_{3} \geq N_{2} \geq U_{1} \geq N_{1} \text { and } N_{2} \geq U_{2} .
$$

\subsection{The transition matrix for a type in a mover partition}

The preceding analysis shows how the Bellman values determine the way that the $4 \times 4$ transition matrix of a type among four states is derived from the $6 \times 4$ matrix of arrival probabilities. For mover partition 1, the transition matrix is the arrival matrix without its second and third rows. That is, it omits the row for unemployment in state 1 and the row for out-of-labor-force in state 2 . The individual described by mover partition 2 has a transition matrix that omits the first and fourth rows of the arrival matrix.

The transition matrix for mover partition 1 (upper panel of Table 3) has 5 distinct jobfinding rates: $\tau_{N, 1,3}$ is the probability of moving to a short-term job from out of the labor force while in the inactive non-work state, $\tau_{N, 1,4}$ is the probability of moving into a longerterm job. $\tau_{U, 1,3}$ and $\tau_{U, 1,4}$ are the similar probabilities into jobs from unemployment while in inactive or activated non-work states. $\tau_{3,4}$ is the probability of moving from a short-term job into a longer-term one.

The transition matrix also has 5 distinct job-losing rates: $\tau_{4,3}$ is the rate from longer-term jobs down to short-term jobs. This captures endogenous layoffs - the "slippery job ladder". $\tau_{3,1}, \tau_{3,2}, \tau_{4,1}$, and $\tau_{4,2}$ are rates of job loss into unemployment or out of the labor force. These may be considered layoffs, discharges, termination of temporary jobs, or quits. $\tau_{N, 1,2}$ is the probability of activation while remaining out of the labor force and $\tau_{U, 2,1}$ is the probability of de-activation while unemployed and activated. The remaining 4 entries are the probabilities of remaining in the same activity-state combination from one month to the next.

Mover partition 2 differs from 1 by the designation of non-work states, conditional on activities. In partition 2, unemployment corresponds to state 1 , whereas in partition 1 , unemployment corresponds to state 2 . In the data, we observe activities but not states. Thus, the estimates of the elements of the transition matrixes among OLF, unemployment, 


\begin{tabular}{cc|cccc}
\hline \hline $\begin{array}{c}\text { Originating } \\
\text { state }\end{array}$ & Activity & \multicolumn{4}{|c}{ Destination state } \\
\hline Partition 1 & & 1 & 2 & 3 & 4 \\
1 & $\mathrm{~N}$ & $\tau_{\mathrm{N}, 1,1}$ & $\tau_{\mathrm{N}, 1,2}$ & $\tau_{\mathrm{N}, 1,3}$ & $\tau_{\mathrm{N}, 1,4}$ \\
2 & $\mathrm{U}$ & $\tau_{\mathrm{U}, 2,1}$ & $\tau_{\mathrm{U}, 2,2}$ & $\tau_{\mathrm{U}, 2,3}$ & $\tau_{\mathrm{U}, 2,4}$ \\
3 & $\mathrm{E}$ & $\tau_{3,1}$ & $\tau_{3,2}$ & $\tau_{3,3}$ & $\tau_{3,4}$ \\
4 & $\mathrm{E}$ & $\tau_{4,1}$ & $\tau_{4,2}$ & $\tau_{4,3}$ & $\tau_{4,4}$ \\
\hline Partition 2 & & & & & \\
1 & $\mathrm{U}$ & $\tau_{\mathrm{U}, 2,2}$ & $\tau_{\mathrm{U}, 2,1}$ & $\tau_{\mathrm{U}, 2,3}$ & $\tau_{\mathrm{U}, 2,4}$ \\
2 & $\mathrm{~N}$ & $\tau_{\mathrm{N}, 1,2}$ & $\tau_{\mathrm{N}, 1,1}$ & $\tau_{\mathrm{N}, 1,3}$ & $\tau_{\mathrm{N}, 1,4}$ \\
3 & $\mathrm{E}$ & $\tau_{3,2}$ & $\tau_{3,1}$ & $\tau_{3,3}$ & $\tau_{3,4}$ \\
4 & $\mathrm{E}$ & $\tau_{4,2}$ & $\tau_{4,1}$ & $\tau_{4,3}$ & $\tau_{4,4}$ \\
\hline \hline
\end{tabular}

Table 3: Transition Probabilities for Mover Partitions in Terms of the Arrival Probabilities

and two kinds of employment under these two partitions are exactly the same. But, given our definition of non-work states 1 and 2, the order of rows and columns of the transition matrixes under the two partitions differ. We designate as state 2 the state in which the jobfinding rate from non-work (either from $\mathrm{N}$ or $\mathrm{U}$ ) is higher. Consequently, if the job-finding rate from $U$ is higher than the job-finding rate from $N, U$ is in state 2 and $N$ is in state 1 , and the mover is in partition 1 . If the job-finding rate from $U$ is lower than the job finding rate from $\mathrm{N}$, the mover is in partition 2. The lower panel of Table 3 shows the transition matrix for partition 2 written in terms of elements from partition 1, shown in the upper panel.

\subsection{Validation of a partition and identification of flow values}

As shown above, given the ranking of the Bellman values in equation (7) through equation (10), we know the transition matrix among the states, which we can then estimate from the data on transitions. The next step is to validate the estimates by determining that there exists a vector of flow values and probability parameters of activities not chosen that combined with the estimated transition probabilities lies in the partition of the type's parameter space that supports the ranking.

If so, the type model is valid and ready to describe behavior. If the model flunks the validity check, it is necessary to try another partition. Because there are only 24 partitions and the validity calculation is undemanding, it is easy to find one that passes the check. Section 7 goes into details about the validation process.

In the partition, the movements of individuals have the same pattern, described purely by the transition probabilities for the partition, for all of the flow values. Behavior is discontin- 
uously different upon crossing into a new partition with its own transition probabilities. The flow values are set-identified in our setup, with data limited to the frequency distribution of transition paths among activities and lacking direct monthly information about wages. We discuss this issue more fully in section 8. Hall and Mueller (2018) use a different survey with information on wages, reservation wages, and offered wages, to make progress on flow values.

\subsection{Ergodic distribution}

A key property of a type model is its ergodic probability distribution over 4 states, defined as the self-replicating 4-vector such that applying the transition matrix to the vector yields a repetition of the vector.

\subsection{Determining the probability of a state path}

The transition matrix of a type, and its associated vector of ergodic probabilities, assign a probability to each of the $4^{8}=65,536$ state paths, each of which specifies which of the four states the hypothetical individual occupies in each of 8 months. These paths run through 1111-1111, 2111-1111, 1211-1111, through to 4444-4444. Were it not for the 8-month gap separating a respondent's first and second appearance in the CPS, the probability would be the product of the ergodic probability of the state in the first month and the transition probabilities for the following 7 transitions. Appendix A describes how the calculation accounts for the 8-month gap.

We obtain the probability of a given activity path by adding together the probabilities of all the state paths that map into the activity path. For example, in the mover case where $s=1$ maps into $\mathrm{N}$ (not in labor force), $s=2$ maps into $\mathrm{U}$ (unemployed), and $s=3$ and $s=4$ map into E (employed), the state paths 1112-3311, 1112-3411, 1112-4311, and 1112-4411, all map into NNNU-EENN, so the probability of the activity path is the sum of the probabilities of those four state paths. The adding-up process generates the vector of $3^{8}=6561$ activity-path probabilities for a type.

\subsection{Implications for activities}

The observed activities of an individual are $a=N$, not in labor force, $a=U$, unemployed, and $a=E$, employed. The function describing the mapping of the partially hidden state variable $s$ to the observed activities $a$ is:

- If $s=1, a=N$ if $N_{1}>U_{1}$ and $a=U$ if $N_{1}<U_{1}$

- If $s=2, a=N$ if $N_{2}>U_{2}$ and $a=U$ if $N_{2}<U_{2}$ 
- If $s=3$ or $4, a=E$

In mover partition 1 , this is

- If $s=1, a=N$

- If $s=2, a=U$

- If $s=3$ or $4, a=E$

The ergodic distribution among activities is simply the ergodic distribution of the states mapped into activities using this rule. For mover partition 1, the ergodic distribution of activities is: probability of $\mathrm{N}=$ probability of state 1 , probability of $\mathrm{U}=$ probability of state 2 , and probability of $\mathrm{E}=$ probability of state $3+$ probability of state 4 .

\subsection{Transition probabilities for unvisited state-activity pairs}

Table 1 has 6 rows of arrival probabilities, while the transition matrix for mover partition 1 has 4 rows, omitting transitions from state 1-activity $U$ and from state 2 -activity $N$. Although these probabilities are not relevant for the transitions among the states and activities that are visited, they are relevant for the Bellman values, because they determine whether the type model actually lies in the mover partition. Further, they would have a role in revealing information about the flow values. We take up these issues in section 8 .

\section{Model for the Population Containing Multiple Types}

The overall model is structured as a probability mixture of personal dynamic programs - that is, the weighted average of the type-model probabilities across state or activity paths, where the weights (the mixing probabilities) are interpreted as the fractions of the population that the various types account for. These weights, denoted $\omega_{\theta}$, are parameters of the model, along with the transition-probability parameters.

\subsection{Choice of types}

Our strategy in building the overall model is to specify two simple types fairly strictly and then to estimate other types quite flexibly. The first simple type is called all- $N$. People of this type choose to be out of the labor force under all realizations of the random variable $j$. They have a single Bellman value, $N_{1}$, and related Bellman equation,

$$
N_{1}=z+\frac{1}{1+r} N_{1}
$$


The path probability vector for this type places probability 1 on the path NNNN-NNNN and zero on all other activity paths. In terms of our definition of partitions of the parameter space, the type is in the two partitions in the category Only $N$ activity (partitions 3 and 4 in Table 2).

The second simple type, called all-E, describes stably employed individuals in longer-term jobs. Their single Bellman value is $E_{4}$; their single Bellman equation is

$$
E_{4}=1+\frac{1}{1+r} E_{4}
$$

and their path probability vector places probability 1 on the path EEEE-EEEE. Returning to our definition of partitions, this is a special case of a mover partition with all the entries of the transition matrix, except for the fourth column, restricted to zero.

Appendix B describes an alternative approach, in which we impose a moderately informative prior pointing in the direction of types all-N and all-E. This approach yields results quite similar to ours, which can be seen as imposing a dogmatic version of the prior.

The other types - called mover types - use the full apparatus of the previous section, to describe the behavior of individuals who are not firmly out of the labor force or employed in longer-term stable jobs. We let the data determine the number of mover types, the values of their parameters, and their weights in the overall model.

Each of the mover types is in one of the two mover partitions.

\subsection{Some general comments on the framework}

A model in our framework describes the experiences of heterogeneous groups of individuals who belong to a relatively small number of types - 5 in our application. Those of a given type behave in accord with a DMP-inspired dynamic program with a small number of possibly hidden states. We solve for the individual's policy function, which records the optimal choice for each random realization.

The model's concept of a partition defines the range of variation of the flow values of time for which the model applies. Within the partition, variation in those flow values does not affect the individual's pattern of labor-market activities. In particular, the same transition probabilities among states apply for all flow values in the partition.

Individuals do not change type. And they do not move from one partition to another. These restrictions imply that the transition probabilities have true structural interpretations. Based on this property, the remainder of the paper estimates transition probabilities for each type and the mixing weights of the types, and demonstrates a variety of implications of the resulting models. 


\begin{tabular}{|c|c|c|c|c|c|c|c|c|c|}
\hline & \multicolumn{9}{|c|}{ Month from entry to survey } \\
\hline & 0 & 1 & 2 & 3 & & 12 & 13 & 14 & 15 \\
\hline $\begin{array}{l}\text { Observation } \\
\text { number }\end{array}$ & 1 & 2 & 3 & 4 & Not & 5 & 6 & 7 & 8 \\
\hline $\begin{array}{l}\text { Example of } \\
\text { the labor } \\
\text { market } \\
\text { activity path }\end{array}$ & 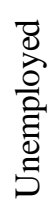 & 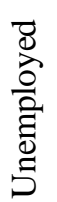 & 茪 & 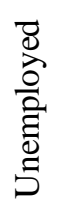 & $\begin{array}{l}\text { interviewed } \\
\text { for } 8 \text { months }\end{array}$ & 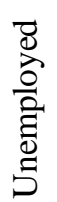 & 营 & 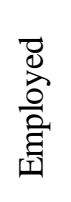 & 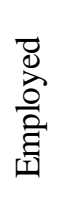 \\
\hline Notation & $\mathrm{U}$ & $\mathrm{U}$ & $\mathrm{N}$ & $\mathrm{U}$ & & $\mathrm{U}$ & E & $\mathrm{E}$ & $\mathrm{E}$ \\
\hline
\end{tabular}

Table 4: Individual Monthly Activity Panels in the CPS

We return to the economics of the model later in the paper. We describe the relation between the parameters - flow values and transition probabilities - and the resulting patterns of labor-market activities found earlier in the paper.

\section{Data}

We use data from the Current Population Survey. Each respondent contributes a path of labor-market activities. Table 4 shows the structure of the data. We consider frequency distributions for women aged 25 through 54 , and men in those age groups. There are about 2.4 million respondents, approximately equally divided between women and men.

Our data are for the years 2014 through 2017. On average, conditions in the labor market, notably the unemployment rate, were close to long-run averages during those years, starting slacker than normal and ending somewhat tighter than normal. Thus we believe our findings describe normal conditions.

Hall and Schulhofer-Wohl (2018) discuss the problem of attrition in the CPS and document its incidence. See Ahn and Hamilton (2019b) for more on this issue. We include the respondents who have complete activity histories, so there could be some bias from our implicit assumption that the included respondents are typical of the population.

Table 5 shows the distribution of the population across the three activities, by length of time the individual has been in the CPS. In principle, the distributions should be the same for each duration. In fact, the table confirms an issue in the CPS called rotation group bias - people tend to be classified more as employed and unemployed and less as out of the labor force when they enter the survey. It is as if continuing to participate in the CPS drives people out of the labor force. We do not think this problem has any material adverse effect on our work. 


\begin{tabular}{lcccc|ccccc}
\hline \hline & \multicolumn{3}{c|}{ First 4 months in survey } & \multicolumn{4}{c}{ Second 4 months in survey } \\
\cline { 2 - 9 } Observation number & 1 & 2 & 3 & 4 & 5 & 6 & 7 & 8 \\
Months from entry to survey & 0 & 1 & 2 & 3 & 12 & 13 & 14 & 15 \\
Fraction employed & 0.792 & 0.788 & 0.788 & 0.789 & 0.792 & 0.792 & 0.791 & 0.792 \\
Fraction unemployed & 0.036 & 0.034 & 0.032 & 0.031 & 0.027 & 0.026 & 0.027 & 0.026 \\
Fraction out of labor force & 0.173 & 0.178 & 0.179 & 0.180 & 0.181 & 0.183 & 0.182 & 0.182 \\
\hline \hline
\end{tabular}

Table 5: Distribution of Population across the Three Activities, by Months in CPS

\begin{tabular}{lcc}
\hline \hline & \multicolumn{2}{c}{ Share, percent } \\
\cline { 2 - 3 } Activity Path & Women & Men \\
\hline EEEE-EEEE & 61 & 77 \\
NNNN-NNNN & 17 & 7 \\
Other & 22 & 16 \\
\hline All & 100 & 100 \\
\hline \hline
\end{tabular}

Table 6: Summary of the Distributions of Activity Paths

Table 6 shows the summary of the distributions of activity paths for 25-54 year old women and for 25-54 year old men.

We need to be clear about how we treat jobs and employment. We measure employment spells, which may include more than one job. As a technical matter, our "short-term job" should be "short-term employment spell" and our "longer-term job" should also refer to a spell. Although the CPS attempts to record job changes within employment spells, during the time span of our data, a change in CPS interview protocols introduced substantial errors in that process. See Fujita, Moscarini and Postel-Vinay (2019).

\section{Statistical Procedure}

We pursue a statistical approach that is a generalization of the statistical models typified by Blanchard and Diamond (1990). It would be impossible for us to do justice to the rich literature that has accumulated since that paper's publication. Our objective is to describe and interpret the individual dynamics of the three observed activities, employment, unemployment, and out-of-the-labor-force. We start with the full joint distribution of the activities from the CPS data, in the form of the frequency of each of the $3^{8}=6561$ possible paths for a respondent during the 8 months reported in the CPS. Some objectives are met by the tabulation of interesting functions of those paths. For example, we show that, among the respondents who were unemployed in the first month of the survey, the frequency distribution of people in the last month of their inclusion in the survey is substantially skewed 
toward unemployment compared to the distribution implied by taking the relevant power of the observed first-order transition matrix found in the data. But other objectives involve a parametric model of the joint distribution. For example, direct tabulation of the frequencies cannot be done for the interesting question of the evolution of the probability of being unemployed in more than three successive months after starting in the survey in unemployment, because the CPS has an 8-month gap in the middle of the period a respondent is in the survey when no record is made of labor-market activity. A parametric model supports interpolation by making use of the record of months 1 through 4, followed by months 13 through 16. The model also supports extrapolation after month 16.

A second major reason for adopting a parametric approach is to implement the idea that the population contains a mixture of types of people. Our preferred model has two pre-defined types, all-N and all-E and three mover types, whose transition probabilities are estimated by the method described in this section. Each mover type has a fairly simple dynamic specification - a first-order Markov process with 4 states. The more complex features of the joint distribution arise from additional parameters interpreted as the fraction of the population belonging to a given type. Models that are mixtures of first-order Markov processes can mimic the dynamics of data that are far from first-order Markov. A leading example is the job-finding rate for the unemployed - the transition probability from unemployment to employment. In the case of two types equally frequent among the newly unemployed, if one type has a job-finding rate of 50 percent per month and another 10 percent per month, the initial job-finding rate will be the average, 30 percent. But in the second month, the composition of the population that remain unemployed shifts in the direction of the group with a low job-seeking rate, and the blended rate falls to 24 percent. After 5 months, the rapid job-finders are mostly depleted and the blended rate is only 13 percent. Thus mixtures of first-order Markov processes can track the duration dependence found in the data.

Another idea that extends the flexibility of the parametric approach is that there is an underlying Markov structure of states, but the observed activities do not fully reveal those states - some information about the states is hidden. We hypothesize two states: short-term job and longer-term job. Workers in short-term jobs have higher job-separation rates than those in longer-term jobs. Shifts in workers from short-term to longer-term jobs behind the scenes result in changes in job-loss rates within the group of employed individuals. Thus hidden states contribute to the ability of the model to match the non-Markov features of the joint distribution of individuals across the three observed activities. Section 5 shows that the results reject a model with only one employment state in favor of a model with the employment states - one with high and one with low separation rate. 


\subsection{Probabilities}

Each type $\theta$ in our model implies a distribution of its activity paths, $\tilde{M}_{\theta}$, a vector of 6561 probabilities. The distribution of types in the population is $\omega$. The probability distribution within the population implied by the model is the mixture, with weights $\omega$, of these distributions,

$$
\tilde{M}=\sum_{\theta} \omega_{\theta} \tilde{M}_{\theta}
$$

For each type $\theta$ and each path $m$, we compute the probability $\tilde{M}_{\theta, m}$ of the path. We start with the type's ergodic distribution and account for the 8 months of unobserved activities between month 4 and month 5 of the observed activities. Details of this step are in Appendix A.

The parameters of the model comprise vectors of state-to-state transition probabilities for each type plus the vector $\omega$ of mixing probabilities. All of these parameters are nonnegative and do not exceed one. In practice, the inequality constraints do not bind. The mixing weights and each row of the transition matrix are also constrained to sum to one.

\subsection{Estimation and sampling distribution of the estimates}

Estimation involves finding the values of the parameters that imply probabilities $\tilde{M}_{m}$ that best fit the observed frequencies in the CPS data, $M_{m}$. Here $m$ indexes the frequency vector over the $3^{8}$ activity paths. The natural starting point for measuring the distance is the likelihood function. The log-likelihood is:

$$
\log L=R \sum_{m} M_{m} \log \tilde{M}_{m}
$$

where $R$ is the number of observations, about 1.2 million of each gender. As usual, we use the inverse of the Hessian matrix of second derivatives of the log-likelihood as an estimate of the covariance matrix of the maximum-likelihood estimates of the 40 distinct parameters. This count is net of the restriction that all of the parameters are probabilities summing to one. There are 3 in each of the 4 rows of the transition matrixes of the 3 mover types (36 transition probabilities in all) plus the 4 distinct mixing probabilities. The reported standard errors are quite small, reflecting the large samples of more than a million women and a million men. We investigated the literature on robust estimation of sampling distributions in the presence of mis-specification, of which White's robust standard errors for regression coefficients constitute the most familiar application in econometrics, but we are not aware of any contributions to this literature applicable to our application, where the observations are not differentiated by observed variables. We also verified that bootstrap standard errors were similar to those from the Hessian. 


\subsection{The tradeoff between the number of types and the number of states}

The family of specifications considered in this paper has two dimensions of complexity and resulting ability to fit a given body of data. These are the number of types and the number of states. With enough states, a single type would be adequate. The proof of this proposition is straightforward: Starting from an original specification with several types, create a single master type with the transition matrixes of the several types down its diagonal. The number of states in the master type would be the product of the number of states in the original types and the number of original types. Selecting the best combination is an art guided by statistical tests.

Computational limits also play a role in this choice. With 20 states, the number of possible state paths is $20^{8}=25,600,000,000$, which would be well beyond the grasp of any known computing facility.

\section{$5 \quad$ Statistical Results}

We carry out estimation separately for women and men. Each mover type has a vector of transition probabilities. We also estimate the mixing parameters, $\omega_{\theta}$, that reveal the relative importance of the types, including the all-N and all-E types. Figure 1 shows the values of the log-likelihood, without multiplication by the sample size. Numbers of types in excess of 5 hardly raise the likelihood.

The types we find are:

1. All- $N$ type, stably out of the labor force (100 percent of the time)

2. High- $N$ mover type, often out of the labor force (50 percent for men and 60 percent for women)

3. High-U mover type, often unemployed (around 30 percent)

4. High-E mover type, often employed (around 90 percent)

5. All-E type, stably fully employed (100 percent)

We label the types according to the resulting ergodic distribution across observed activities - employment, unemployment and OLF. It turns out that the ergodic probabilities in the observed activities for the three mover types, for both women and men, are vastly different. The High-N type has the highest ergodic probability in OLF among the mover types, the High-U type has the highest ergodic probability in unemployment among the mover types, 


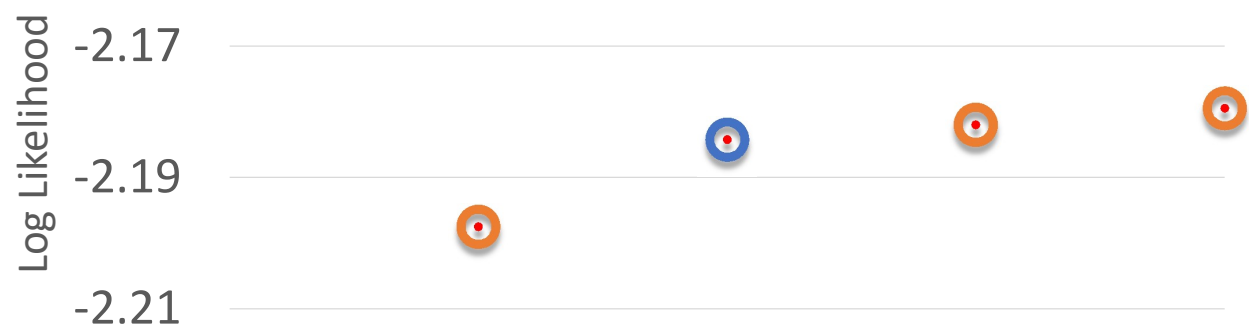

$-2.23$

$-2.25$
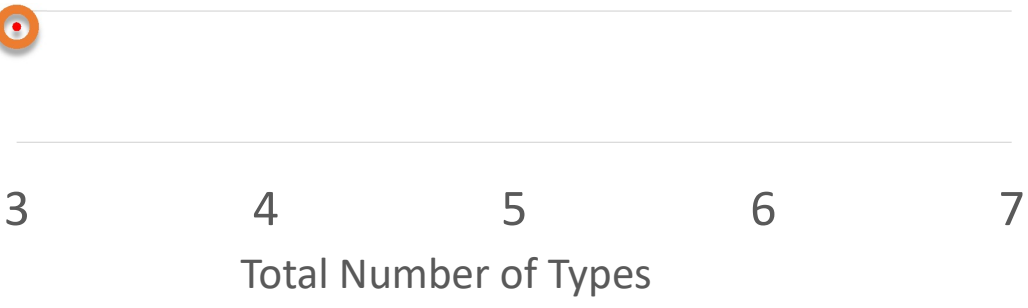

Figure 1: Likelihood by Number of Types, Women

and the High-E type has the highest ergodic probability in employment among the mover types.

\subsection{Parameter estimates}

Table 7 shows the estimated values of the parameters of the model for women and men, respectively, with standard errors in parentheses. In general, the results suggest that it is feasible to estimate the transition probabilities for each of the 3 mover types, plus the 5 values of the mixing weights, $\omega_{\theta}$.

A few observations pop out of the table. There are substantial differences in transition probabilities and type weights across types but the types themselves are similar across genders. Persistence in short-term jobs is much lower than in longer-term jobs for all types except High-E men. And all types remain in longer-term jobs with high probability.

The model has 16 separate transitions. Hence it is difficult to think through many of the implications of the model from its battery of transition probabilities. In the remainder of the paper, we put the model through a variety of demonstrations of its implications. We begin with those relating to movements among the states considered in the model and observed activities. Then we bring in the implications including economic values to buttress the view that the working-age population contains a minority of individuals whose economic 


\begin{tabular}{|c|c|c|c|c|c|c|c|}
\hline \multirow{2}{*}{ Parameter } & \multirow{2}{*}{ Description } & \multicolumn{3}{|c|}{ Women } & \multicolumn{3}{|c|}{ Men } \\
\hline & & $\begin{array}{c}\text { High- } N \\
\text { Type }\end{array}$ & $\begin{array}{c}\text { High-U } \\
\text { Type }\end{array}$ & $\begin{array}{c}\text { High-E } \\
\text { Type }\end{array}$ & $\begin{array}{c}\text { High-N } \\
\text { Type }\end{array}$ & $\begin{array}{c}\text { High-U } \\
\text { Type }\end{array}$ & $\begin{array}{c}\text { High-E } \\
\text { Type }\end{array}$ \\
\hline$\tau_{\mathrm{N}, \mathrm{N}}$ & Persist in OLF & $\begin{array}{c}0.902 \\
(0.001)\end{array}$ & $\begin{array}{c}0.614 \\
(0.005)\end{array}$ & $\begin{array}{c}0.285 \\
(0.003)\end{array}$ & $\begin{array}{c}0.864 \\
(0.001)\end{array}$ & $\begin{array}{c}0.426 \\
(0.007)\end{array}$ & $\begin{array}{c}0.219 \\
(0.003)\end{array}$ \\
\hline$\tau_{\mathrm{N}, \mathrm{U}}$ & Advance to unemployment from OLF & $\begin{array}{c}0.032 \\
(0.000)\end{array}$ & $\begin{array}{c}0.318 \\
(0.004)\end{array}$ & $\begin{array}{c}0.064 \\
(0.002)\end{array}$ & $\begin{array}{c}0.061 \\
(0.001)\end{array}$ & $\begin{array}{c}0.467 \\
(0.006)\end{array}$ & $\begin{array}{c}0.052 \\
(0.002)\end{array}$ \\
\hline$\tau_{\mathrm{N}, \mathrm{S}}$ & Advance to short-term job from OLF & $\begin{array}{c}0.052 \\
(0.003)\end{array}$ & $\begin{array}{c}0.050 \\
(0.005)\end{array}$ & $\begin{array}{c}0.486 \\
(0.041)\end{array}$ & $\begin{array}{c}0.062 \\
(0.003)\end{array}$ & $\begin{array}{c}0.070 \\
(0.009)\end{array}$ & $\begin{array}{c}0.139 \\
(0.020)\end{array}$ \\
\hline$\tau_{\mathrm{N}, \mathrm{L}}$ & Advance to longer-term job from OLF & $\begin{array}{c}0.014 \\
(0.003)\end{array}$ & $\begin{array}{c}0.018 \\
(0.004)\end{array}$ & $\begin{array}{c}0.164 \\
(0.038)\end{array}$ & $\begin{array}{c}0.013 \\
(0.003)\end{array}$ & $\begin{array}{c}0.037 \\
(0.009)\end{array}$ & $\begin{array}{c}0.591 \\
(0.021)\end{array}$ \\
\hline$\tau_{\mathrm{U}, \mathrm{N}}$ & Drop to OLF from unemployment & $\begin{array}{c}0.521 \\
(0.006)\end{array}$ & $\begin{array}{c}0.179 \\
(0.001)\end{array}$ & $\begin{array}{c}0.077 \\
(0.002)\end{array}$ & $\begin{array}{c}0.431 \\
(0.005)\end{array}$ & $\begin{array}{c}0.129 \\
(0.001)\end{array}$ & $\begin{array}{c}0.051 \\
(0.001)\end{array}$ \\
\hline$\tau_{\mathrm{U}, \mathrm{U}}$ & Persist in unemployment & $\begin{array}{c}0.322 \\
(0.006)\end{array}$ & $\begin{array}{c}0.702 \\
(0.002)\end{array}$ & $\begin{array}{c}0.338 \\
(0.008)\end{array}$ & $\begin{array}{c}0.417 \\
(0.005)\end{array}$ & $\begin{array}{c}0.742 \\
(0.002)\end{array}$ & $\begin{array}{c}0.370 \\
(0.005)\end{array}$ \\
\hline$\tau_{\mathrm{U}, \mathrm{S}}$ & Advance to short-term job from unemployment & $\begin{array}{c}0.055 \\
(0.003)\end{array}$ & $\begin{array}{c}0.066 \\
(0.004)\end{array}$ & $\begin{array}{c}0.100 \\
(0.017)\end{array}$ & $\begin{array}{c}0.057 \\
(0.005)\end{array}$ & $\begin{array}{c}0.084 \\
(0.010)\end{array}$ & $\begin{array}{c}0.506 \\
(0.042)\end{array}$ \\
\hline$\tau_{\mathrm{U}, \mathrm{L}}$ & Advance to longer-term job from unemployment & $\begin{array}{c}0.103 \\
(0.003)\end{array}$ & $\begin{array}{c}0.053 \\
(0.003)\end{array}$ & $\begin{array}{c}0.485 \\
(0.023)\end{array}$ & $\begin{array}{c}0.095 \\
(0.005)\end{array}$ & $\begin{array}{c}0.045 \\
(0.010)\end{array}$ & $\begin{array}{c}0.073 \\
(0.042)\end{array}$ \\
\hline$\tau_{\mathrm{S}, \mathrm{N}}$ & Drop to OLF from short-term job & $\begin{array}{c}0.490 \\
(0.027)\end{array}$ & $\begin{array}{c}0.133 \\
(0.008)\end{array}$ & $\begin{array}{c}0.154 \\
(0.014)\end{array}$ & $\begin{array}{c}0.493 \\
(0.020)\end{array}$ & $\begin{array}{c}0.105 \\
(0.013)\end{array}$ & $\begin{array}{c}0.011 \\
(0.004)\end{array}$ \\
\hline$\tau_{\mathrm{S}, \mathrm{U}}$ & Drop to unemployment from short-term job & $\begin{array}{c}0.033 \\
(0.003)\end{array}$ & $\begin{array}{c}0.335 \\
(0.019)\end{array}$ & $\begin{array}{c}0.014 \\
(0.001)\end{array}$ & $\begin{array}{c}0.061 \\
(0.004)\end{array}$ & $\begin{array}{c}0.367 \\
(0.042)\end{array}$ & $\begin{array}{c}0.074 \\
(0.006)\end{array}$ \\
\hline$\tau_{\mathrm{S}, \mathrm{S}}$ & Persist in short-term job & $\begin{array}{c}0.325 \\
(0.009)\end{array}$ & $\begin{array}{c}0.366 \\
(0.013)\end{array}$ & $\begin{array}{c}0.442 \\
(0.017)\end{array}$ & $\begin{array}{c}0.326 \\
(0.011)\end{array}$ & $\begin{array}{c}0.314 \\
(0.044)\end{array}$ & $\begin{array}{c}0.907 \\
(0.004)\end{array}$ \\
\hline$\tau_{\mathrm{S}, \mathrm{L}}$ & Advance to longer-term job from short-term job & $\begin{array}{c}0.152 \\
(0.036)\end{array}$ & $\begin{array}{c}0.166 \\
(0.020)\end{array}$ & $\begin{array}{c}0.391 \\
(0.011)\end{array}$ & $\begin{array}{c}0.120 \\
(0.020)\end{array}$ & $\begin{array}{c}0.214 \\
(0.047)\end{array}$ & $\begin{array}{c}0.008 \\
(0.004)\end{array}$ \\
\hline$\tau_{\mathrm{L}, \mathrm{N}}$ & Drop to OLF from longer-term job & $\begin{array}{c}0.037 \\
(0.023)\end{array}$ & $\begin{array}{c}0.005 \\
(0.002)\end{array}$ & $\begin{array}{c}0.017 \\
(0.006)\end{array}$ & $\begin{array}{c}0.020 \\
(0.011)\end{array}$ & $\begin{array}{c}0.007 \\
(0.002)\end{array}$ & $\begin{array}{c}0.055 \\
(0.002)\end{array}$ \\
\hline$\tau_{\mathrm{L}, \mathrm{U}}$ & Drop to unemployment from longer-term job & $\begin{array}{c}0.007 \\
(0.001)\end{array}$ & $\begin{array}{c}0.030 \\
(0.004)\end{array}$ & $\begin{array}{c}0.028 \\
(0.001)\end{array}$ & $\begin{array}{c}0.013 \\
(0.001)\end{array}$ & $\begin{array}{c}0.033 \\
(0.005)\end{array}$ & $\begin{array}{c}0.007 \\
(0.002)\end{array}$ \\
\hline$\tau_{\mathrm{L}, \mathrm{S}}$ & Drop to short-term job from longer-term job & $\begin{array}{c}0.041 \\
(0.028)\end{array}$ & $\begin{array}{c}0.017 \\
(0.008)\end{array}$ & $\begin{array}{c}0.146 \\
(0.010)\end{array}$ & $\begin{array}{c}0.025 \\
(0.015)\end{array}$ & $\begin{array}{c}0.029 \\
(0.012)\end{array}$ & $\begin{array}{c}0.004 \\
(0.002)\end{array}$ \\
\hline$\tau_{\mathrm{L}, \mathrm{L}}$ & Persist in longer-term job & $\begin{array}{c}0.916 \\
(0.005)\end{array}$ & $\begin{array}{c}0.948 \\
(0.003)\end{array}$ & $\begin{array}{c}0.808 \\
(0.006)\end{array}$ & $\begin{array}{c}0.942 \\
(0.005)\end{array}$ & $\begin{array}{c}0.932 \\
(0.009)\end{array}$ & $\begin{array}{c}0.935 \\
(0.002)\end{array}$ \\
\hline$\omega_{\theta}$ & Mover type weights & $\begin{array}{c}0.154 \\
(0.001)\end{array}$ & $\begin{array}{c}0.060 \\
(0.001)\end{array}$ & $\begin{array}{c}0.150 \\
(0.003)\end{array}$ & $\begin{array}{c}0.072 \\
(0.001)\end{array}$ & $\begin{array}{c}0.054 \\
(0.002)\end{array}$ & $\begin{array}{c}0.152 \\
(0.001)\end{array}$ \\
\hline$\omega_{\text {All-N }}$ & All-N type weight & & $\begin{array}{c}0.134 \\
(0.001)\end{array}$ & & & $\begin{array}{c}0.057 \\
(0.000)\end{array}$ & \\
\hline$\omega_{\text {All-E }}$ & All-E type weight & & $\begin{array}{c}0.502 \\
(0.002)\end{array}$ & & & $\begin{array}{c}0.664 \\
(0.002)\end{array}$ & \\
\hline
\end{tabular}

Table 7: Parameter Values 
opportunities are roughly equal in value, so they move back and forth among non-market activities, unemployment, and short-term employment.

\section{$5.2 \quad$ Heterogeneity is substantial}

We estimate substantial heterogeneity across types and sizeable weights for each type.

Table 8 displays the ergodic distributions within each type, for women and men, calculated from the estimated transition probabilities. The all-N and all-E types are concentrated entirely, by definition, in their designated states. The mover types have unconcentrated distributions.

High- $\mathrm{N}$ men spend over half of their time out of the labor force but almost 30 percent of their time in longer-term work. High- $\mathrm{U}$ men spend 34 percent of their time looking for work, but also spend 50 percent of their time at longer-term work, and only 10 percent out of the labor force. High-E men spend 90 percent of their time employed-38 percent in short-term and 52 percent in longer-term jobs, and only 5 percent in unemployment or OLF. The two columns at the right compare the model's ergodic distributions for the populationthe sum of the types weighted by their weighted fractions in the population - to the actual distribution in the data. The latter lumps together the two employment categories. The match across the three observed activities is exact to the three digits reported.

The bottom panel of the table breaks down the standard statistics for labor-force activity across the types. The participation rate among high- $\mathrm{N}$ types is low, at 49 percent, and, of course, zero for the all-N types, while it is above 90 percent for the other types. The unemployment rate is sky-high for the high-U types, fairly high for the high-N types, and normal or zero for high-E and all-E types. The two columns at the right show the data and the model's statistics, which again match the data almost exactly.

The bottom line of the table repeats the estimated distribution of the population across types from the previous table. Each of the five types has a non-trivial weight in the population. Among men, 66 percent are all-E type and 6 percent are all-N type. The remaining 28 percent are mover types: 7 percent are high-N movers, 5 percent are high-U movers and 15 percent are high-E movers. Table 6 shows that the share of EEEE-EEEE paths in the sample of men is 77 percent. Our estimates of the types weights imply that 66 percentage points comes from all-E type and the remaining 11 percentage points comes from the mover types.

The individuals are heterogeneous in the sense of being spread across the five types all the way from a disinclination or inability to participate in the market at all, in one type, and

total devotion to participation, in another type, with substantial fractions closer to even, 


\begin{tabular}{|c|c|c|c|c|c|c|c|c|}
\hline \multirow{2}{*}{ Activity } & \multirow{2}{*}{ Labor market state } & \multirow{2}{*}{$\begin{array}{c}\text { All-N } \\
\text { type }\end{array}$} & \multicolumn{3}{|c|}{ Mover types } & \multirow{2}{*}{$\begin{array}{c}\text { All-E } \\
\text { type }\end{array}$} & \multirow{2}{*}{$\begin{array}{c}\text { Full } \\
\text { model }\end{array}$} & \multirow{2}{*}{ Data } \\
\hline & & & $\overline{H i g h-N}$ & $\overline{H i g h-U}$ & High-E & & & \\
\hline & & \multicolumn{7}{|c|}{ Women } \\
\hline $\mathrm{N}$ & Non-work* & 100 & 63 & 15 & 7 & 0 & 25.1 & 25.1 \\
\hline $\mathrm{U}$ & Non-work** & 0 & 4 & 28 & 4 & 0 & 2.8 & 2.8 \\
\hline \multirow{2}{*}{$\mathrm{E}$} & Work in short-term job & 0 & 7 & 6 & 24 & 0 & 5.0 & \multirow{2}{*}{72.1} \\
\hline & Work in longer-term job & 0 & 27 & 51 & 65 & 100 & 67.1 & \\
\hline \multicolumn{2}{|c|}{ Unemployment rate,\% } & - & 10 & 33 & 4 & 0 & 3.8 & 3.8 \\
\hline \multicolumn{2}{|c|}{ Employment to population ratio,\% } & 0 & 34 & 57 & 89 & 100 & 72.1 & 72.1 \\
\hline \multicolumn{2}{|c|}{ Labor force participation rate,\% } & 0 & 37 & 85 & 93 & 100 & 74.9 & 74.9 \\
\hline \multicolumn{2}{|c|}{ Weights in the population,\% } & 13 & 15 & 6 & 15 & 50 & 100 & \\
\hline & & \multicolumn{7}{|c|}{ Men } \\
\hline $\mathrm{N}$ & Non-work* & 100 & 51 & 10 & 5 & 0 & 10.6 & 10.6 \\
\hline $\mathrm{U}$ & Non-work ${ }^{* *}$ & 0 & 7 & 34 & 5 & 0 & 3.2 & 3.1 \\
\hline \multirow{2}{*}{$\mathrm{E}$} & Work in short-term job & 0 & 7 & 7 & 38 & 0 & 6.7 & \multirow{2}{*}{86.3} \\
\hline & Work in longer-term job & 0 & 36 & 50 & 52 & 100 & 79.6 & \\
\hline \multicolumn{2}{|c|}{ Unemployment rate,\% } & - & 14 & 37 & 6 & 0 & 3.5 & 3.5 \\
\hline \multicolumn{2}{|c|}{ Employment to population ratio,\% } & 0 & 43 & 57 & 90 & 100 & 86.3 & 86.3 \\
\hline \multicolumn{2}{|c|}{ Labor force participation rate,\% } & 0 & 49 & 90 & 95 & 100 & 89.4 & 89.4 \\
\hline \multicolumn{2}{|c|}{ Weights in the population, $\%$} & 6 & 7 & 5 & 15 & 66 & 100 & \\
\hline
\end{tabular}

Note: Non-work* refers to the non-activated non-work state for high-N and high-U types

and to the activated non-work state for high-E type. Non-work** refers to the activated

non-work state for high-N and high-U types and to the non-activated non-work state for high-E type.

Table 8: Heterogeneous Ergodic Distributions across States and Activities 


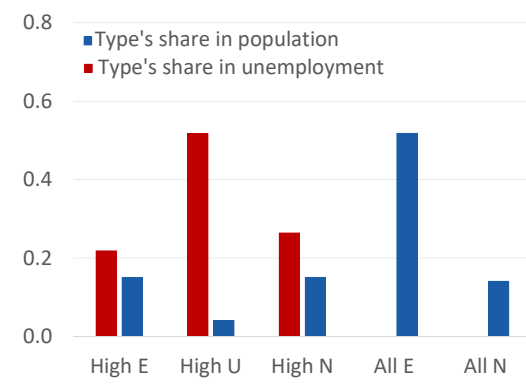

(a) Women

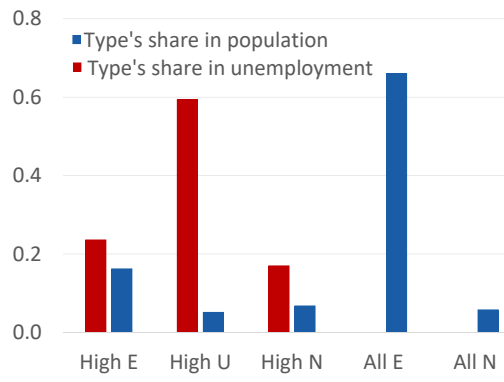

(b) Men

Figure 2: Most Unemployment Comes from a Small Segment of the Population

with varying mixtures of activities over time. The types are similar for women. So most of the heterogeneity arises within each gender and relatively little across genders.

\subsection{Unemployment arises from a small fraction of the population}

Figure 2 shows the concentration of unemployment in the high- $U$ type. That type accounts for 60 percent of all unemployment among men even though they are only 5 percent of the population. The high-N and high-E types that are either largely out of the labor force or largely in longer-term employment have significant roles in the population but minor roles in unemployment. Unemployment among women is similarly concentrated in the high-U type.

\subsection{Circling reveals the low-employment type}

We define circling as frequent movement among labor-market states: OLF, unemployment, and, possibly, short-term employment. We measure circling as the percent of a randomly drawn sample of people who move from one month to the next from one of those states to another of those states. Table 9 , column 1 shows the incidence of circling between OLF and unemployment - paths include frequent NU and UN pairs. Table 9 , column 2 shows the incidence of circling among OLF, unemployment, and short-term jobs - paths include frequent SU, US, SN, NS, UN, and NU pairs (where S denotes a short-term job). High-U men circle between $\mathrm{U}$ and $\mathrm{N}$ with probability 8.8 percent; high- $\mathrm{N}$ men, with probability 6 percent; and high-E men circle with a probability of only 0.5 percent. Circling is much more common among the high- $\mathrm{U}$ and high-N than in the high-E type.

In the CPS, the path from non-employment to employment often involves circling between unemployment and out of labor force. An approach in the existing literature on frequent 


\begin{tabular}{c|cc}
\hline \hline & $\begin{array}{c}\text { Percent of population making } \\
\text { circling transitions each month }\end{array}$ \\
\hline Type & $\begin{array}{r}\text { Between } \\
U \text { and } N\end{array}$ & $\begin{array}{c}\text { Among } U, N, \\
\text { and Short-Term } \\
\text { Jobs }\end{array}$ \\
\hline & \multicolumn{2}{|c}{ Women } \\
High- $N$ & 3.9 & 10.9 \\
High- $U$ & 9.9 & 15.1 \\
High-E & 0.8 & 8.6 \\
\hline & \multicolumn{3}{|c}{ Men } \\
High- $N$ & 6.0 & 13.1 \\
High- $U$ & 8.8 & 15.7 \\
High- $E$ & 0.5 & 7.2 \\
\hline \hline
\end{tabular}

Table 9: Circling

changes between unemployment and out of the labor force tries to correct what it regards as classification errors in the CPS. A recent practice is to treat transition reversals between unemployment and OLF as classification error and to re-code such transitions into one of the two continuous non-employment statuses. Elsby, Hobijn and Şahin (2015) call this "DeNUNification" because it replaces a NUN sequence with NNN.

Our model, in contrast, accepts the CPS data as a record of behavior. Among the three mover types, our model attributes frequent changes between unemployment and OLF to high- $\mathrm{U}$ and high-N types. These types have much lower ergodic probability in employment as compared to high-E type. Consequently, the model finds that frequent circling between unemployment and out of labor force in the data is associated with lower employment rates. Kudlyak and Lange (2018) make a related point by showing that individuals with labor market histories of NUN have five times higher monthly probability of finding a job than those with the three consecutive months of $\mathrm{N}$.

This is not to say that the CPS survey is free of classification error. Instead, our view is that frequent changes between reported labor force statuses contain information about respondent's types.

How do we reconcile our view with the results of the Re-Interview Survey conducted by the BLS during 1977 through 1982? In the re-interview, the labor force status of a fraction of respondents was reclassified based on interviews conducted one week after the original interview (Abowd and Zellner (1985), Poterba and Summers (1986), and Jones and Riddell (1999)). As a result of the the re-interview, 99 percent of respondents who initially were 
reported as being employed were retained in that classification and 99 percent of respondents who were initially reported as being OLF were continued as OLF - see Table 6 in Abowd and Zellner. Only 90 percent of the respondents who initially reported as being unemployed were retained as unemployed. 2.3 percent of them were re-classified as employed and 7.7 percent as out of the labor force. The results of the re-interview survey provide the main support for the misclassification-error hypothesis.

Through the lens of our model, the individuals who can be easily reclassified from one labor market status to another upon re-interview are those whose values of search or no search are very similar. The individuals who remain in the original classification upon the re-interview are those for whom the distinction between values of search and non-search are sufficiently dissimilar. We believe that retaining the original coding of the interview result is superior to fixed arbitrary rules such as recoding NUN as NNN. In any case, the evidence in Kudlyak and Lange's paper powerfully rejects the validity of rewriting activity paths. In other words, though doubtless there are classification errors in the CPS, rewriting the data based on observables such as NUN is probably not the right cure.

\subsection{Short-term and longer-term jobs}

The model hypothesizes two kinds of job, short-term and longer-term, to capture the decline with tenure seen in the data on separation rates. With a single separation rate, the fraction of workers who separate does not change with job tenure. But in the data, separation rates decline rapidly in the early months of employment. For men, the separation rate after one month on the job is 15 percent, whereas the rate after two months is 8 percent. Our estimation uses all the information in the data to infer that there are two groups among the employed - the workers with high separation rates separate rapidly and the survivors after only a few months have much lower rates. Table 10 shows that in all 6 mover types (3 types of women and 3 of men), the separation rate from longer-term jobs is substantially lower than the rate from short-term jobs. The large difference confirms the ability of our estimation method to distinguish short-term jobs from longer-term ones.

The model does not assign individual jobs to the short-term or longer-term categories. But it does imply a probability that a particular job in a particular sequence of activities is longer-term rather than short-term. The situation is described by the activities of the respondent in the 8 observed months. For a randomly chosen activity path in the data, we can calculate probability that the employment activity is a short- versus longer-term job using transition matrixes of the types and the types' weights. 


\begin{tabular}{c|ccccc}
\hline \hline \multirow{2}{*}{ Parameter } & $\begin{array}{c}\text { Separation Rate } \\
\text { from }\end{array}$ & $\begin{array}{c}\text { High-N } \\
\text { type }\end{array}$ & $\begin{array}{r}\text { High-U } \\
\text { type }\end{array}$ & $\begin{array}{c}\text { High-E } \\
\text { type }\end{array}$ \\
\hline & \multicolumn{5}{c}{ Women } \\
$1-\tau_{\mathrm{S}, \mathrm{S}}$ & Short-term job & 0.675 & 0.634 & 0.093 \\
$1-\tau_{\mathrm{L}, \mathrm{L}}$ & Longer-term job & 0.084 & 0.052 & 0.192 \\
\hline & & Men & & \\
$1-\tau_{\mathrm{S}, \mathrm{S}}$ & Short-term job & 0.674 & 0.686 & 0.093 \\
$1-\tau_{\mathrm{L}, \mathrm{L}}$ & Longer-term job & 0.058 & 0.068 & 0.065 \\
\hline \hline
\end{tabular}

Table 10: Separation Rates from Short- and longer-term Jobs

\subsection{State paths}

Figure 3 and Figure 4 show the paths of states following unemployment for the three mover types for men and women. The paths are the probability distributions of future states, conditional on being unemployed in month zero. The distribution across states converges over time, fairly rapidly, to the ergodic distribution. Types differ by the ergodic distribution they converge to and the speed of convergence.

For men, the high-E type rapidly converges to the lowest ergodic probability in unemployment and in OLF among the three types. However, the high-E types convergence to the ergodic probability of longer-term employment is slow. This is because the type initially overshoots its ergodic probability in short-term jobs and takes a long time to converge to its ergodic level. The high-E type's ergodic probability of short-term employment is much higher as compared to the other two types. The high-E type's ergodic probability of longer-term employment is only 1 percentage point higher than that of the high-U type. By definition, the high- $\mathrm{U}$ and high-N types converge to the highest ergodic probabilities in unemployment and OLF, respectfully.

For women, the dynamics of the high-E type is much faster as compared to the high-E men, without overshooting in short-term jobs.

\section{Evaluating the Success of the Model in Capturing Key Features of the Data}

In this section, we describe a variety of views into the actual frequencies of activity paths in the CPS and the success of the model in matching them. We study the differences between statistics computed from the actual frequencies and the corresponding probabilities of those statistics implied by our model. 


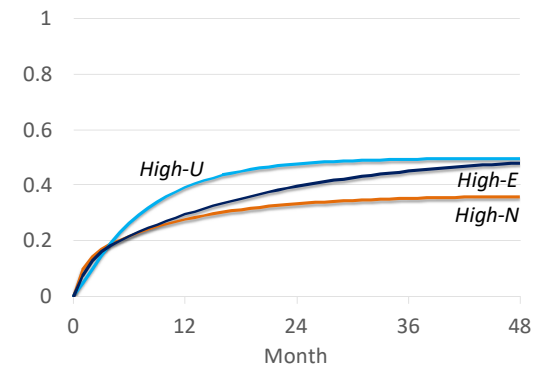

(a) To longer-term job

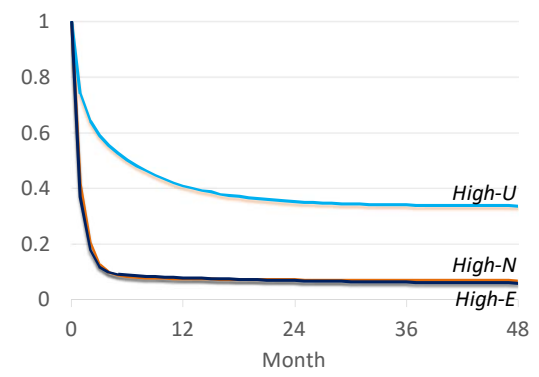

(c) Remaining in unemployment

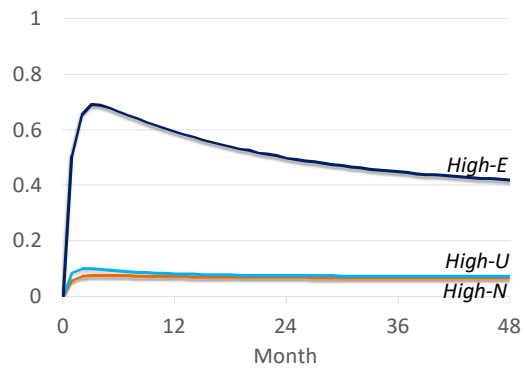

(b) To short-term job

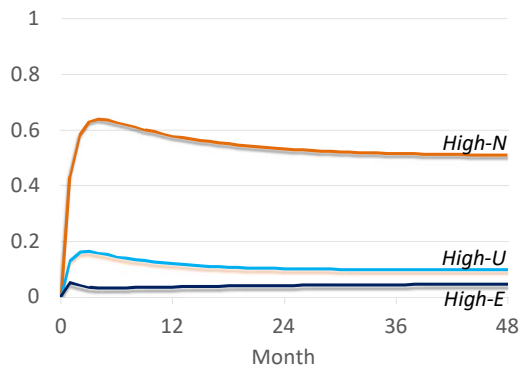

(d) To out of labor force

Figure 3: Paths of States Following Unemployment, by Type, for Men 


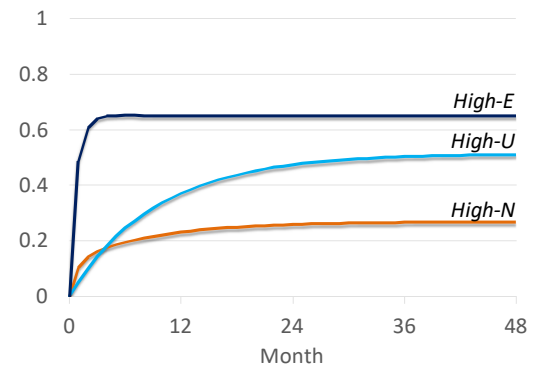

(a) To longer-term job

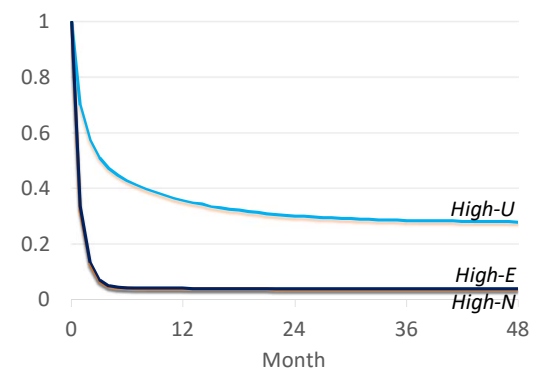

(c) Remaining in unemployment

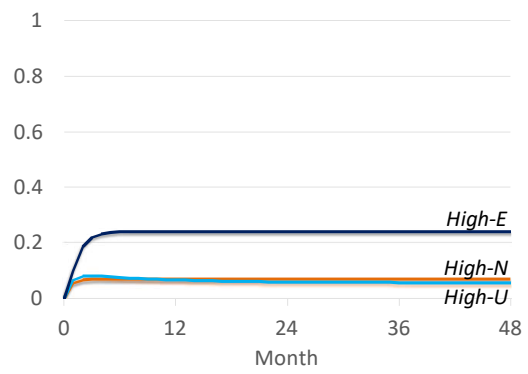

(b) To short-term job

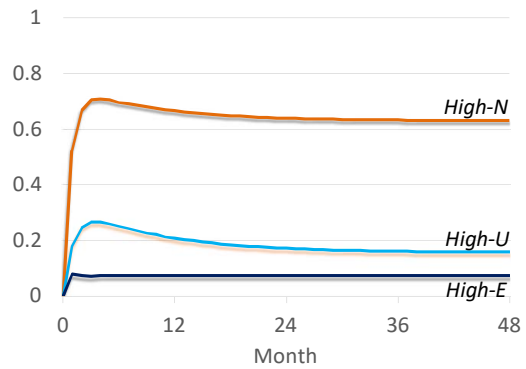

(d) To out of labor force

Figure 4: Paths of States Following Unemployment, by Type, for Women 


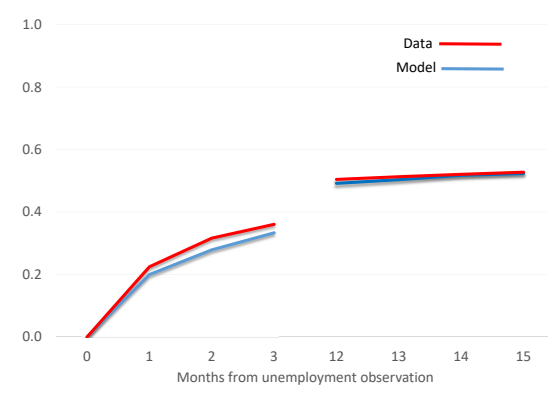

(a) Women

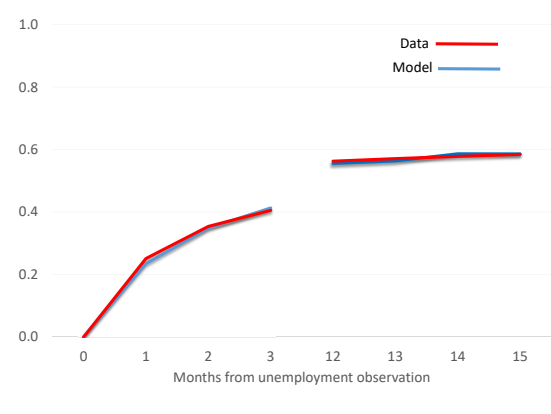

(b) Men

Figure 5: Paths of Employment Following Unemployment

We start in Figure 5 with results on the re-employment process. For each demographic group, we show the probability of employment by the number of months following a month when an individual is unemployed. The curves are concave, and start at zero by construction. These curves describe the quite rapid initial progress into employment (both short-term and longer-term), which our model attributes to the ease of finding short-term jobs. By month 3, the process has gone most of the way to its asymptote of around 50 percent. The re-employment process comes nowhere near the overall ergodic employment rate for the population, because the selection of individuals who are unemployed in the first place implies, in the model, that the individual has a mover type, and, in the data, that the individual does not come from a part of the population with low likelihoods of unemployment.

The match of model to data is outstanding for the months before the eight-month break in the CPS schedule for the men and women groups. The discrepancies between model and data arise essentially entirely from the specification discrepancies we mentioned in the statistics section-absent them, probabilities calculated from the model match the data precisely, because they are derived from a representation of the data that includes all of its relevant properties.

Figure 6 shows the tracking of the model to the data for all three observed activities, for women. The model understates unemployment somewhat, starting at two months, and correspondingly overstates out-of-the-labor-force, given that the match is so good for employment.

Figure 7 studies the success rate of the unemployed in a given month in terms of being employed in later months. The one-month success rate is fairly high, at about 25 percent. But further progress is much slower. Even 7 months later, only 59 percent are at work. This 


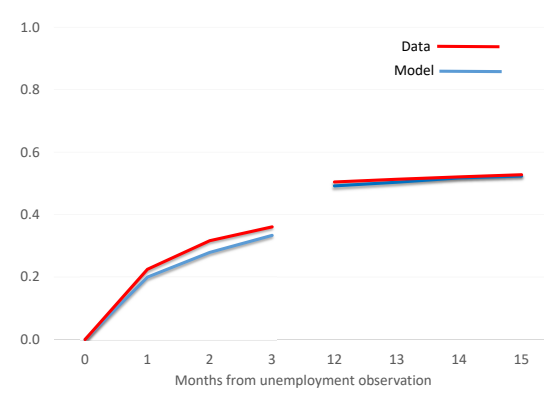

(a) Employment

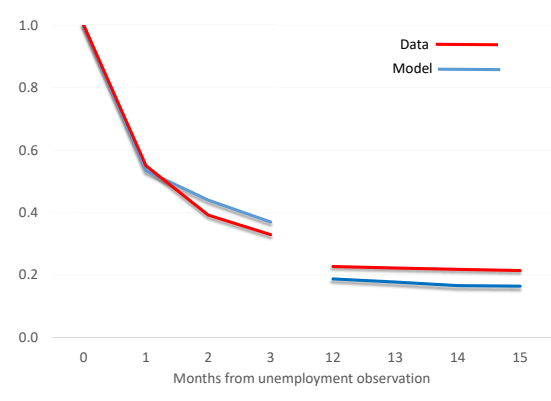

(b) Unemployment

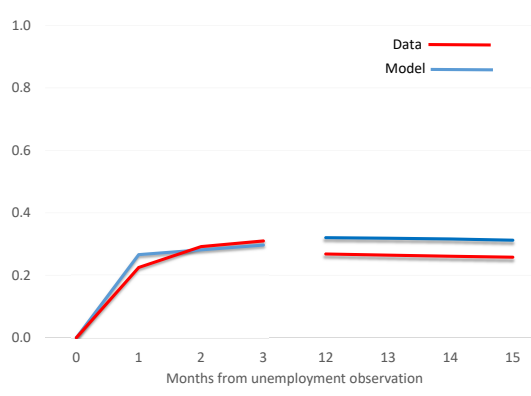

(c) OLF

Figure 6: Paths of Three Activities Following Unemployment, Women 


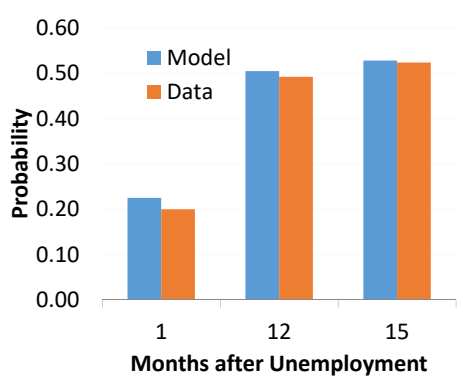

(a) Women

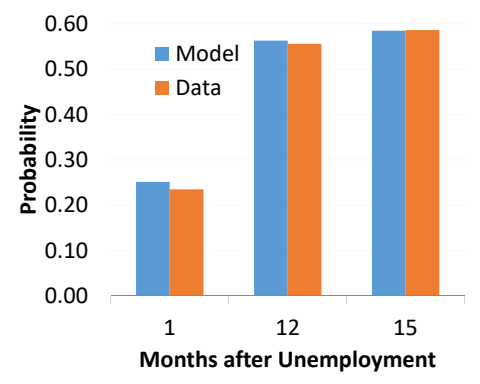

(b) Men

Figure 7: Success Rates in Becoming Employed after Being Unemployed

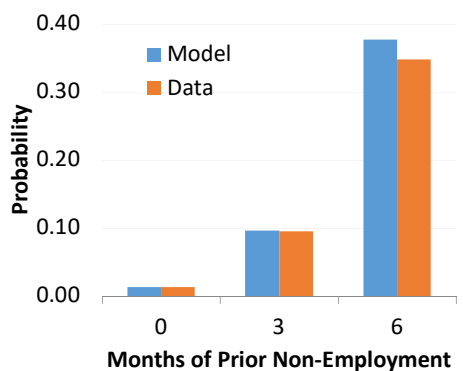

(a) Women

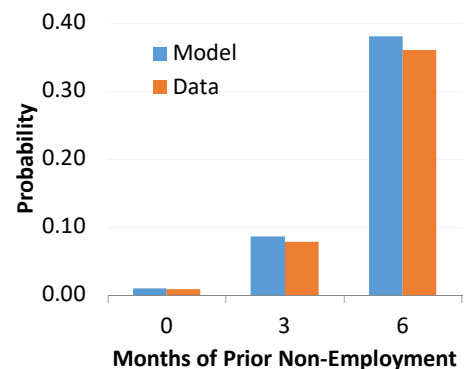

(b) Men

Figure 8: Probability of Job Loss in Month 7 by Number of Months of Non-Work in Earlier Months

is another illustration of the failing of the traditional assumption of uniform job-finding rates among the unemployed.

Figure 8 displays the probability that a worker in month 7 of the CPS will lose that job in month 8 , broken down by the number of months of work in months 1 through 6 . The job loss probability is just over one percent if the worker had worked in every prior month, but reaches a stunning 40 percent if the job was brand new in month 7 and the worker spent the previous 6 months not working. Our model replicates this property of labor-market dynamics. 


\begin{tabular}{c|ccc|ccc}
\hline \hline & \multicolumn{5}{|c}{ To activity } \\
\cline { 2 - 7 } & \multicolumn{3}{|c}{ 1 month later } & \multicolumn{3}{c}{ 15 months later } \\
\cline { 2 - 7 } & $\mathrm{E}$ & $\mathrm{U}$ & $\mathrm{N}$ & $\mathrm{E}$ & $\mathrm{U}$ & $\mathrm{N}$ \\
\hline From activity & \multicolumn{3}{|c}{ Data } & \multicolumn{4}{c}{ Data } \\
$\mathrm{E}$ & 0.981 & 0.009 & 0.010 & 0.954 & 0.018 & 0.027 \\
$\mathrm{U}$ & 0.254 & 0.581 & 0.165 & 0.586 & 0.201 & 0.212 \\
$\mathrm{~N}$ & 0.076 & 0.044 & 0.880 & 0.175 & 0.037 & 0.788 \\
& \multicolumn{3}{|c|}{ Full model } & \multicolumn{4}{c}{ Full model } \\
$\mathrm{E}$ & 0.981 & 0.009 & 0.010 & 0.954 & 0.021 & 0.024 \\
$\mathrm{U}$ & 0.251 & 0.593 & 0.155 & 0.585 & 0.255 & 0.160 \\
$\mathrm{~N}$ & 0.079 & 0.047 & 0.874 & 0.197 & 0.048 & 0.754 \\
& \multicolumn{3}{|c}{ First-order model } & \multicolumn{3}{c}{ First-order model } \\
$\mathrm{E}$ & 0.981 & 0.009 & 0.010 & 0.880 & 0.027 & 0.093 \\
$\mathrm{U}$ & 0.254 & 0.581 & 0.165 & 0.794 & 0.036 & 0.170 \\
$\mathrm{~N}$ & 0.076 & 0.044 & 0.880 & 0.704 & 0.045 & 0.251 \\
\hline \hline
\end{tabular}

Table 11: Model v. Single First-Order Markov in the Activities, Men

\subsection{Comparison of the model to one with a single first-order Markov process in the activities}

Table 11 compares the one-month and 15-month transition rates in the data, in our model and in one that is based on a single first-order Markov structure in the observed activities for men. We compute the one-month transition rates from the average across the 6 monthly transitions for the respondents. We raise that transition matrix to the 15 th power to display its implications for the longest transition measured in the CPS.

Our model fits the one-month transition rates almost perfectly. The first-order model fits the one-month transition rates perfectly by construction. On the other hand, the firstorder model fits the 15-month transitions poorly, because the first-order assumption does not hold. It understates the persistence of employment, unemployment, and out-of-the-laborforce. The understatement is especially notable for the non-employment activities. This issue is discussed in Krueger et al. (2014) and Hall and Schulhofer-Wohl (2018). Correspondingly, the first-order model overstates transitions out of the states. For example, for men, the probability of transition from out of labor force to employment in the data is 0.174 while in the first-order model it is 0.702 . Similarly, the probability of transition from employment to out of labor force in the data is 0.027 while in the first-order model it is 0.093 .

Our model is much more successful in accounting for movements among three activities and the persistence of the activities. There are two main aspects of our model that deviate from the first-order assumption. First, our model contains a mixture of types. Second, for the non-mover types, even though the states follow Markov processes, the observed activities 
do not. This is because the states are partially hidden - there are 4 states and 3 activities. This heterogeneity in our model allows it to replicate the transition probabilities over longer horizons in the data-higher persistence of the activities and lower transition rates among activities than the first-order model predicts.

Our success in accounting for 15-month transitions shows that longer-span transition frequencies are key to our results. Although it is hard to assign responsibility across all 6561 individual moments, it does seem clear that longer-span transition frequencies rank high in importance among those moments.

\section{$7 \quad$ Further Discussion of the Economic Model}

\subsection{Interpreting the transition probabilities}

We emphasize that the transition probabilities estimated in this paper are organic to a model in the DMP class. Our estimated parameters are not merely those of a statistical reduced form. They are structural. They are invariant to fairly large changes in the personal environment - changes that keep the individual within the same partition in terms of the ranking of Bellman values.

We recover the arrival probabilities of shocks and opportunities from observed transitions, so the types also differ by arrival probabilities. Accordingly, each type has its own transition rate from $\mathrm{U}$ to $\mathrm{N}$. We should note that our portrayal of transition probabilities differs from what is found in some of the related literature.

An alternative style of modeling is the following. With respect to one transition, say job-finding, the person receives offers from time to time. When one arrives, the person compares it to a reservation value and accepts if it meets that value. The probability of a transition from unemployment to working is the product of the probability of arrival of an offer and the probability that the offer meets the reservation wage. Heterogeneity in the job-finding probability across people arises from the heterogeneity in the offer arrival rate, in the distribution of offered wags, and in the reservation wage chosen by the person based on the value of time in non-work activities. See Hall and Mueller (2018) for a detailed development of this approach using excellent data on reservation wages.

Our approach, and the one implicit in a large volume of research typified by Blanchard and Diamond (1990), is to roll the probabilities together and model that probability. It will be higher in populations where the job offer distribution has a lot of mass at wages above the reservation wage, either because the wages are good or the person is willing to work at low wages. 


\subsection{Numbering the states, mover types partitions, and validation}

Our estimation delivers, for each type, a 4 by 4 transition matrix among OLF, unemployment, and two kinds of employment. After estimating a transition matrix, we re-order the rows and columns of the matrix to comply with our naming conventions for states:

1. The non-work state with higher probability of finding a job (short- or longer-term) is designated as state 2 . The other non-work state is state 1 .

2. The employment state with higher persistence is designated as state 4. The employment state with lower persistence is state 3 .

Both of these rules eliminate ties in likelihood between behaviorally equivalent transition matrixes; they do not have any effect on the estimates or interpretation of the results.

We estimate the transition probabilities for the mover types under the assumption that the types are in mover partition 1 or 2 . Table 7 shows that the high- $\mathrm{N}$ and high-U types have higher probability of finding a job (short- or longer-term) from unemployment than from OLF. Thus, according to our definition of states, for these types, unemployment corresponds to state 2 (activated non-work), and OLF corresponds to state 1 (non-activated non-work). In contrast, the high-E type has higher probability of finding a job from OLF than from unemployment. Thus, for the high-E type, unemployment corresponds to state 1, nonactivated non-work, and OLF corresponds to state 2, activated non-work. High-N and high- $\mathrm{U}$ types are in mover partition 1 and high-E type is in mover partition 2. This holds true for women and men.

We say that a set of estimated transition probabilities is validated as belonging to a partition if there is a vector of candidate flow values $f$ and non-estimated transition probabilities that is within the partition. Our program for finding extremal values finds validity if there is a feasible solution that satisfies all of the constraints including the ordering of the Bellman values corresponding to the partition. We have found that all of the type-level models discussed in this paper are valid.

\section{Information about Economic Values Contained in Our Results}

\subsection{Extracting information from our estimates}

Our model produces estimates of transition probabilities across the states. Section 1 shows that in order to arrive at the transition probabilities we need to know the ranking of the Bellman values associated with different choices, but we do not need to know the Bellman 
values themselves. Once we know the ranking, so we know the choices, we can estimate the transition parameters from the observed activities in the data.

Any flow values that are consistent with the ranking, given the estimated transition probabilities, are consistent with the observed transitions in the data. A simple example in Appendix C may help clarify the information that our model yields about the flow values. The basic point is that the distribution of activity paths imposes inequalities on flow valuesthey are set-identified, not point-identified.

Our model point identifies only the transition probabilities among the states and activities that are chosen. As discussed in section 1, the transition matrix we estimate is missing two rows of arrival probabilities that appear in the complete matrix of arrival probabilities in Table 1. But data on actual transitions from those choices is absent because, in the mover partition 1 , nobody is ever in state 1 with activity $U$ or state 2 with activity N. Although the transition probabilities in these rows are not estimated in our statistical procedure, they are not irrelevant. They enter the ranking of Bellman values that eventually define the choices. The influence of potential options that are never actually exercised - "off-equilibrium" in modern economic parlance - is a familiar topic in many kinds of economic models.

In our model, the distribution of activity paths imposes inequalities on two kinds of parameters. First, the model contains three unknown flow values, $z, b$, and $w_{3}$. Second, the model contains transition probabilities associated with activities not chosen. We derive bounds on the two kinds of parameters by finding extreme values over all the unknown values.

We write the Bellman system in equation (1) through equation (6) as

$$
\left[\begin{array}{c}
N_{1} \\
U_{1} \\
N_{2} \\
U_{2} \\
E_{3} \\
E_{4}
\end{array}\right]=\left[\begin{array}{c}
z \\
b \\
z \\
b \\
w_{3} \\
1
\end{array}\right]+\frac{1}{1+r}\left[\begin{array}{cccc}
\tau_{N, 1,1} & \tau_{N, 1,2} & \tau_{N, 1,3} & \tau_{N, 1,4} \\
\tau_{U, 1,1} & \tau_{U, 1,2} & \tau_{U, 1,3} & \tau_{U, 1,4} \\
\tau_{N, 2,1} & \tau_{N, 2,2} & \tau_{N, 2,3} & \tau_{N, 2,4} \\
\tau_{U, 2,1} & \tau_{U, 2,2} & \tau_{U, 2,3} & \tau_{U, 2,4} \\
\tau_{3,1} & \tau_{3,2} & \tau_{3,3} & \tau_{3,4} \\
\tau_{4,1} & \tau_{4,2} & \tau_{4,3} & \tau_{4,4}
\end{array}\right]\left[\begin{array}{c}
N_{1} \\
U_{1} \\
N_{2} \\
U_{2} \\
E_{3} \\
E_{4}
\end{array}\right]
$$

We let $x=\left[z, b, w_{3}, \tau_{1}, \ldots, \tau_{6}\right]$ be the vector of 9 unknowns, 3 flow values and 3 values of each set of arrival probabilities, net of the restriction that they sum to one. Given candidate values for the unknowns, we solve this linear equation system and verify that it satisfies the conditions that define the relevant partition. For example, for mover 1, $E_{4} \geq E_{3} \geq U_{2} \geq N_{1} \geq U_{1}$ and $U_{2} \geq N_{2}$.

To derive bounds on the elements of $x$ and Bellman values implied by our estimates of the observable transition probabilities, we let $i$ index the unknown element and $x_{-i}$ denote the 8 other unknown elements apart from $x_{i}$. For example, for mover partition 1 , we consider 


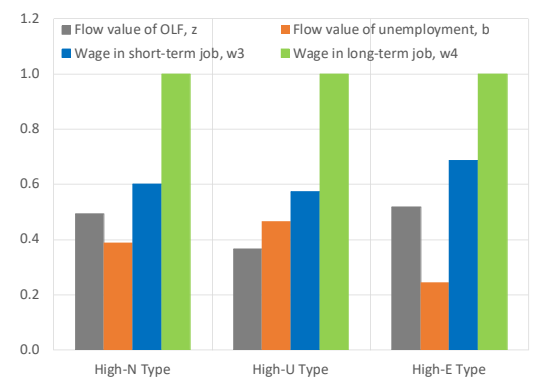

(a) Women

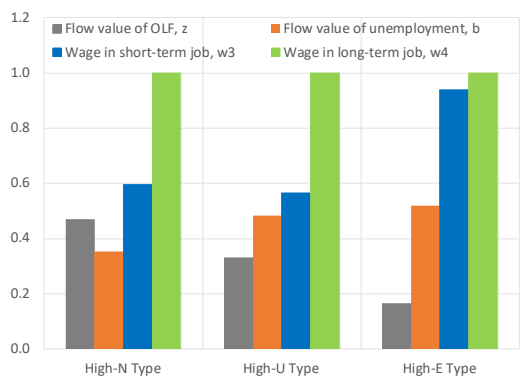

(b) Men

Figure 9: Typical Flow Values

the program

$$
\max _{x_{-i}, B} f_{i} \text { subject to } B=f+\frac{1}{1+r} T B, E_{4} \geq E_{3} \geq U_{2} \geq N_{1} \geq U_{1}, \text { and } U_{2} \geq N_{2},
$$

(where $B, f$, and $T$ have obvious definitions) and the similar program to find the minimum. These programs deliver 18 associated extremal vectors. We also find upper and lower bounds on sums of the flow values: $b+z, b+w_{3}, z+w_{3}$, and $b+z+w_{3}$, with 8 more extremal vectors. We calculate 26 extremal vectors in all.

We calculate average values of the unknowns across the 26 vectors, as indicators of the typical flow values, the unmeasured arrival probabilities, and the Bellman values. We label these values as typical because they lie in the strict interior of the partition. They do not have further statistical properties. We have verified that the resulting typical values of the Bellman values satisfy the ordering conditions for partition 1 for high-N and high-U types and for partition 2 for the high-E type.

\subsection{Flow values}

Figure 9 shows the typical flow values for women and men. From left to right, the bars represent the values of out-of-labor-force, $z$, unemployment, $b$, wage of short-term job, and 1, the normalized wage of a longer-term job, for the three mover types: high-N, high-U, and high-E. Men have slightly lower values of time spent out of the labor market for high-N and high-U, and substantially lower values for the high-E type. The wage of the short-term job is always lower than for the longer-term job, but only slightly for high-E men. 


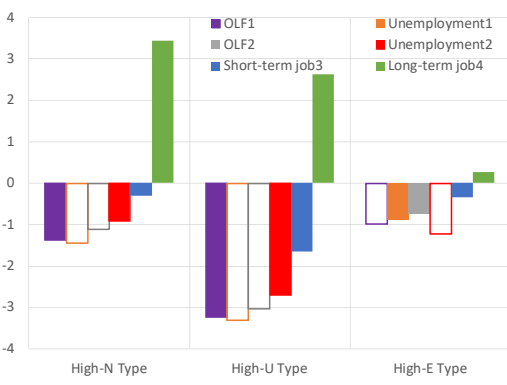

(a) Women

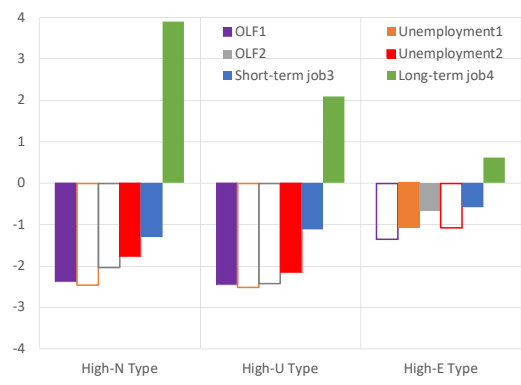

(b) Men

Figure 10: Centered Typical Bellman Values

\subsection{Bellman values}

Figure 10 shows the typical Bellman values by state. The levels of the Bellman values depend on the flow values. To facilitate a comparison of the dispersion of Bellman values across individual states for different 9-element parameter vectors within a type, we display the Bellman values as deviations from their ergodic mean. Because we normalize flow values so that $w_{4}=1$, the unit of magnitude of the Bellman values is the type's one-month earnings in a longer-term job. When making comparisons between women and men, it is important to keep in mind that each is measured relative to earnings in longer-term jobs of workers of the same gender.

Across types, the dispersion of values from working and non-working is small for the highE type and large for the low-employment types, high-N and high-U. This feature does not result from the differences in flow values across types. Instead, it is the consequence of the differences in the types' transition matrices. For the high-E type, unemployment and OLF are much less persistent states than for the low-employment types. Second, for the high-E type, the job-finding probability from unemployment or OLF is much higher than for the low-employment types. Consequently, even if a high-E individual finds himself unemployed or out of the labor force in a particular month, this situation is quite transitory.

Bellman values represent the expected value of an individual's economic life for the indefinite future, counting the flow values of time spent out of the labor market and unemployed, plus the wage earned less any disamenity of working. For both men and women, the expected value of future economic life is much less volatile for the high-E type than for either of the other types. Although, under our assumption of risk neutrality, high volatility imposes no extra cost to the other types, in a more realistic setting with risk aversion, there would 
be an extra cost. The benefits of smoothing policies such as unemployment insurance is concentrated among the 12 percent of the population in high- $\mathrm{N}$ and high- $\mathrm{U}$ types.

\subsection{Economic portraits of the types}

For each of the 5 types, we integrate and discuss results from both phases of our study: transition probabilities and economic values. We cover:

- The partition holding the type

- The ergodic distribution among states

- Job-finding rate while out of labor force $\left(\tau_{\mathrm{N}, 1,3}+\tau_{\mathrm{N}, 1,4}\right)$

- Job-finding rate while unemployed $\left(\tau_{\mathrm{U}, 1,3}+\tau_{\mathrm{U}, 1,4}\right)$

- Job-losing rate while in short-term job $\left(\tau_{3,1}+\tau_{3,2}\right)$

- Job-losing rate while in longer-term job $\left(\tau_{4,1}+\tau_{4,2}\right)$

- Persistence of out of labor force $\left(\tau_{1,1}\right)$

- Persistence of unemployment $\left(\tau_{2,2}\right)$

- Flow values while out of the labor force $(z)$ and unemployed $(b)$, and wage in short-term job $\left(w_{3}\right)$, as ratios to wage in longer-term job

- Average Bellman value, weighted by ergodic probabilities, interpreted as the long-run economic value that an individual receives from time out of the labor force, time looking for work, and time working, as measured by the flow values. The average values are measured in units of the wage in longer-term jobs received by the gender and type under consideration. Thus the average Bellman value measures how efficiently an individual converts earning power into lifetime economic value, not absolute economic value.

- Centered Bellman values for those inactive and out of the labor force $\left(N_{1}\right)$, active and out of labor force $\left(N_{2}\right)$, inactive and unemployed $\left(U_{1}\right)$, active and unemployed $\left(U_{2}\right)$, employed in a short-term job $\left(E_{3}\right)$, and employed in a longer-term job $\left(E_{4}\right)$, all expressed as deviations from the weighted average Bellman value

Table 12 summarizes our findings about the mover types, in terms of the measures just listed. The upper panel shows that high-N women spend 63 percent of their time out of the labor force. Their job-finding rates are low from both $\mathrm{N}$ and $\mathrm{U}$. Their job-losing rates 
from short-term job are high, but their job-losing rates from longer-term jobs are low. If the high-N type finds a longer-term job, it lasts. These women flow into $\mathrm{N}$ at normal rates, but persist in $\mathrm{N}$ to a much greater extent than do the other types. Women's flow values while out of the labor force for the high-N type are higher than for the high- $U$ type but similar to that of the high-E type. Thus the single factor accounting for the low participation rate of type high-N women is their low job-finding rates as compared to the high-E type, which presumably are the result of a moderate incentive to work, as measured by $1-z$, and fewer acceptable job opportunities when searching actively or passively.

The right side of the upper panel of Table 12 applies to high-N men. They share key characteristics with high-N women - high ergodic probability of non-participation, low jobfinding rates, high job-losing rates from short-term jobs and low job-losing rates from longerterm jobs. In contrast to the high- $\mathrm{N}$ women, their flow value of non-participation is much higher than for high-U or high-N type. Thus, these men have low participation rates because of low job-finding rates and high flow values of nonparticipation.

Male high- $\mathrm{N}$ types have higher lifetime economic values relative to their earning power than do women, mainly because the men spend 36 percent of their time in longer-term, higher paying jobs, whereas women spend 27 percent.

The pattern of centered Bellman values for both women and men of the high-N type tells an important story about their labor-market experiences. Both women and men spend at least half of their time out of the labor market, at a monthly rate $z$ of about half what they would earn in a longer-term job. As a result, a woman's value of future economic activities is 1.38 months of earnings lower than their average value. She also has a lower expected lifetime value when unemployed and when employed in a short-term job. All of these low values are offset by the fact that, for 27 percent of the time, she is employed in a longer-term job paying a monthly flow rate of 1 . When so employed, her lifetime value, measured by the Bellman value, is 3.43 months of earnings above average. Her fairly small chance of gaining a longer-term job, and its wage of 1, well above her value of time out of the labor market, imparts considerable volatility to her lifetime economic well being. High-N men also have similar patterns of volatile Bellman values.

The middle panel of Table 12 describes the economic experiences of the high- $\mathrm{U}$ types. Women of this type spend 28 percent of their time unemployed, and men spend 34 percent. Among the high- $U$ types, unemployment is persistent as compared to other types. Women also spend 15 percent of their time out of the labor force, and the men, 10 percent. They both work 57 percent of their time, mainly in longer-term jobs. Like the high- $\mathrm{N}$ types, they have low job-finding probabilities, around 10 percent per month, compared to the high-E 


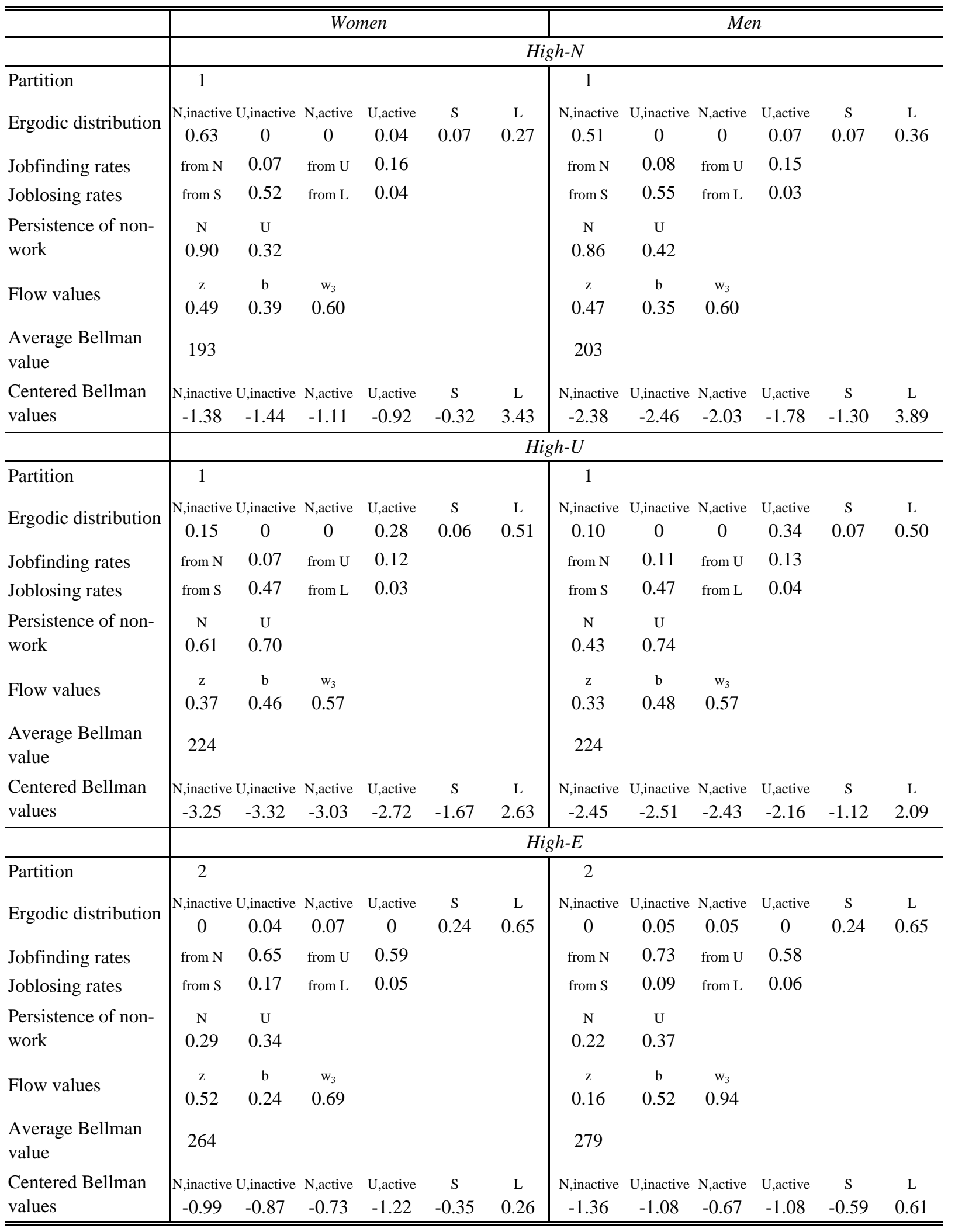

Table 12: Measures Describing the Mover Types 
types. And like the high-N types, they have normal job-losing rates. Their propensity to high unemployment again traces to their low rates of finding a job after losing one.

The high- $U$ men and women are tied in terms of lifetime economic value - all of their parameters are quite similar across gender. This type also faces substantial volatility of lifetime well-being from their pattern of occasional employment at a flow value well above the value they incur when unemployed or out of the labor force. Women swing from -2.72 months when unemployed to +2.63 when holding a longer-term job, and men from -2.16 to 2.09 .

The bottom panel of Table 12 shows that high-E men gain a higher lifetime value from their activities per unit of earning power than do women. The main reason is that men earn more in short-term jobs than do women. The big difference between the high-E types and the two other types is high job-finding rates. Whereas those rates are around 10 percent per month for high- $\mathrm{N}$ and high- $\mathrm{U}$, they are around 60 percent for high-E. Job-losing rates and flow values are similar to the other types, except that the flow value for men when out of the labor force is quite a bit lower, at 0.16. The allocation of time among the high-Es is different from the other types, thanks to the ready availability of replacement jobs upon job loss. Men and women spend 89 percent of their time working. Women spend 4 percent unemployed, and 7 percent out of the labor force, while men spend 5 percent unemployed and 5 percent out of the labor force.

The all-E types encounter much less volatility in lifetime economic value than do the other types. A woman goes from +0.26 to -0.62 upon losing a job and becoming unemployed, and a man from +0.61 to -1.08 . The low volatility arises from the ease of replacing a lost job.

\section{Related Literature}

Rust (1994) discusses identification and estimation in the class of models that we consider for each of our types, but does not deal with heterogeneity modeled as mixtures of types. Shibata (2015) proposes a hidden state Markov model of individual labor market dynamics. He finds a high-order overall transition matrix among hidden states and lets the observed distribution across observed statuses be a linear function of the hidden states. Shibata appeals to an identification theorem in Allman, Matias and Rhodes (2009). He offers meagre interpretation of his results - his main point is that that his more general setup nests the standard model based on one-month transitions, and that a test of the standard model against the more general model overwhelmingly rejects the standard model in favor of more subtle dynamics. See also Feng and Hu (2013) for a related model. Alvarez, Borovičková and Shimer (2017) focus on the long-standing problem of separating the effects of heterogeneity from those of 
duration dependence in a model of the job-finding hazard. They characterize heterogeneity with in a continuous distribution of job-seeker types. Ahn and Hamilton (2019a) consider two types in a model describing the critical role of unobserved heterogeneity.

Hall (1995) offers a simple model of the job-finding process that includes brief interim jobs as part of the explanation of the persistence of unemployment. Pries (2004) builds a formal model that includes interim jobs. Cole and Rogerson (1999) points out that observed high job-finding rates and relatively low separation rates are inconsistent with the persistence of unemployment in the specification following Mortensen and Pissarides (1994). Farber (1994) finds high worker separation hazard at monthly frequency. Hyatt and Spletzer (2017) and Hyatt and Spletzer (2013) document the high incidence of very brief jobs. Böheim and Taylor (2002) show that jobs following a spell of unemployment last for fewer months than those following an earlier job.

Morchio (2019) examines long-run issues in individual earnings dynamics. He finds evidence that unemployment summed over workers' lifetimes is concentrated in a relatively small fraction of workers. Using the NLSY79, he finds that two-thirds of prime-age unemployment in a cohort is accounted for by 10 percent of workers. He finds that time spent in unemployment when a worker is young is a powerful predictor of time spent in unemployment during prime-age. He argues that ex ante heterogeneity is required to explain the facts.

Our work is related to a huge literature on the experiences of workers following displacement, defined as the loss of a job with at least several years of tenure. Jacobson, LaLonde and Sullivan (1993) is an important early contribution. Fallick (1996), Kletzer (1998), and Farber (2015) summarize others. Davis and von Wachter (2011) uses high-quality administrative data on post-displacement earnings and discusses the integration of this line of research with the DMP modeling tradition. Jarosch (2015) shows how the anticipation of likely job loss influences careers. Gagliarducci (2005) investigates repeated temporary jobs in Italian data. Eliason and Storrie (2006) use Swedish data on matched workers and employers to study long-run post-displacement experiences. Chan and Huff Stevens (2001) measure employment-rate depression following displacement among older workers. Jung and Kuhn (2017) provide empirical evidence on heterogeneity in job stability and develop a life-cycle search model to explain the facts. Menzio, Telyukova and Visschers (2016) develop a lifecycle model of the labor market in which different worker-firm matches have different quality. Krusell, Mukoyama, Rogerson and Sahin (2017) build a model of the aggregate labor market that features standard labor supply forces and frictions to study the cyclical properties of gross worker flows across employment, unemployment, and nonparticipation. 


\section{Concluding Remarks}

Our model makes sense out of the 16-month spans of individual paths of labor-market activity recorded in the Current Population Survey. Some people, presumably those with substantial match-specific job capital, are employed in all eight observations. Others, with consistently better opportunities at home rather than in the job market, are out of the labor force in all eight observations. We account for these two types, but most of our modeling effort goes into accounting for people who move around, sometimes out of the labor force, sometimes unemployment, and sometimes working. We portray them as pursuing personal dynamic programs that respond to random events in their lives.

An important part of our model is its distinction between short-term and longer-term jobs. We use only the realizations of job duration that are recorded in the CPS to make this distinction. We show that short-term employment is poised between search that occurs while jobless and longer-term jobholding.

All of our focus in this paper is on personal dynamics. Our estimation relies on data for a boring period in US labor-market history, when the market was neither too cold nor too hot. A next step in this investigation is to look at a period of sharp aggregate change in the labor market, starting in 2008.

We identify substantial heterogeneity in individual labor market dynamics. Some people face such low flow values in non-market activity relative to market activity that they work continuously. Our all-E type captures this category in the population. Some people face higher flow values in a job than in a non-market activity; if they lose a job, they tend to find another fairly soon through intensive search. Our high-E mover type has a much lower typical flow value out of the labor market and much higher job-finding rates than do other types. Some people have close to equal flow values from work and non-work, and tend to circle through jobs, search, and non-market activities. Our high-U type and especially our high-N mover type have values of $z$ closer to 1 than the high-E mover type. Our high-U and high-N types engage in much more circling than does the high-E type. Some people have generally higher values in non-market activities and take jobs seldom or not at all. Our all-N type specializes in non-market activities.

We find that most unemployment comes from a small segment of the population, the high-U mover type. Frequent circling between unemployment, OLF and short-term jobs reveals low employment mover types. Short-term jobs play a role in the job-finding process

related to the role of unemployment. Short-term jobs is a stop-gap jobs for high-employment mover types, and a part of circling for low-employment mover types. 
Because of their high job-finding rates, and despite their low flow values of non-work, the volatility of the high-employment type's Bellman values from work and non-work is lower than for low-employment types.

\section{References}

Abowd, John M. and Arnold Zellner, "Estimating Gross Labor-Force Flows," Journal of Business and Economic Statistics, 1985, 3 (3), 254-283.

Ahn, Hie Joo and James D. Hamilton, "Heterogeneity and Unemployment Dynamics," Journal of Business and Economic Statistics, 2019.

and __ , "Measuring Labor-Force Participation and the Incidence and Duration of Unemployment," 2019. University of California San Diego.

Allman, Elizabeth S., Catherine Matias, and John A. Rhodes, "Identifiability of Parameters in Latent Structure Models with Many Observed Variables," The Annals of Statistics, 2009, 37 (6A), 3099-3132.

Alvarez, Fernando, Katarína Borovičková, and Robert Shimer, "Decomposing Duration Dependence in a Stopping Time Model," 2017. University of Chicago.

Blanchard, Olivier J. and Peter A. Diamond, "The Cyclical Behavior of the Gross Flows of U.S. Workers," Brookings Papers on Economic Activity, 1990, (2), 85-143.

Böheim, René and Mark P. Taylor, "The Search for Success: Do the Unemployed Find Stable Employment?," Labour Economics, 2002, 9 (6), 717-735.

Chan, Sewin and Ann Huff Stevens, "Job Loss and Employment Patterns of Older Workers," Journal of Labor Economics, 2001, 19 (2), 484-521.

Cole, Harold L. and Richard Rogerson, "Can the Mortensen-Pissarides Matching Model Match the Business-Cycle Facts?," International Economic Review, 1999, 40 (4), 933959.

Davis, Steven J. and Till von Wachter, "Recessions and the Costs of Job Loss," Brookings Papers on Economic Activity, Fall 2011, (2), 1-55.

Eliason, Marcus and Donald Storrie, "Lasting or Latent Scars? Swedish Evidence on the Long-Term Effects of Job Displacement," Journal of Labor Economics, 2006, 24 (4), $831-856$. 
Elsby, Michael W.L., Bart Hobijn, and Ayşegül Şahin, "On the Importance of the Participation Margin for Labor Market Fluctuations," Journal of Monetary Economics, 2015, 72, $64-82$.

Fallick, Bruce C, "A Review of the Recent Empirical Literature on Displaced Workers," ILR Review, 1996, 50 (1), 5-16.

Farber, Henry S., "The Analysis of Interfirm Worker Mobility," Journal of Labor Economics, 1994, 12 (4), 554-593.

— _ "Job Loss in the Great Recession and its Aftermath: U.S. Evidence from the Displaced Workers Survey," Working Paper 21216, National Bureau of Economic Research May 2015.

Feng, Shuaizhang and Yingyao Hu, "Misclassification Errors and the Underestimation of the US Unemployment Rate," American Economic Review, 2013, 103 (2), 1054-70.

Fujita, Shigeru, Giuseppe Moscarini, and Fabien Postel-Vinay, "Measuring Employer-toEmployer Reallocation," July 2019. Yale University.

Gagliarducci, Stefano, "The Dynamics of Repeated Temporary Jobs," Labour Economics, 2005, $12(4), 429-448$.

Hall, Robert E., "Lost Jobs," Brookings Papers on Economic Activity, 1995, (1), 221-273. and Andreas I. Mueller, "Wage Dispersion and Search Behavior: The Importance of Non-Wage Job Values," Journal of Political Economy, 2018, 126 (4), 1594-1637. and Sam Schulhofer-Wohl, "Measuring Job-Finding Rates and Matching Efficiency with Heterogeneous Jobseekers," American Economic Journal: Macroeconomics, 2018, $10(1), 1-32$.

Hyatt, Henry R. and James R. Spletzer, "The Recent Decline in Short Duration Jobs," October 2013.

_ _ and _ _ "The Recent Decline of Single Quarter Jobs," Labour Economics, 2017, 46, $166-176$.

Jacobson, Louis S., Robert J. LaLonde, and Daniel G. Sullivan, "Earnings Losses of Displaced Workers," American Economic Review, 1993, 83 (4), 685-709.

Jarosch, Gregor, "Searching for Job Security and the Consequences of Job Loss," December 2015. Princeton University. 
Jones, Stephen R.G. and W Craig Riddell, "The Measurement of Unemployment: An Empirical Approach," Econometrica, 1999, 67 (1), 147-162.

Jung, Philip and Moritz Kuhn, "Earnings Losses and Labor Mobility Over the Life Cycle," 2017. CESifo Working Paper Series 6552, CESifo Group Munich.

Kletzer, Lori G, "Job Displacement," Journal of Economic Perspectives, 1998, 12 (1), 115136.

Krueger, Alan B., Judd Cramer, and David Cho, "Are the Long-Term Unemployed on the Margins of the Labor Market?," Brookings Papers on Economic Activity, Spring 2014.

Krusell, Per, Toshihiko Mukoyama, Richard Rogerson, and Aysegul Sahin, "Gross Worker

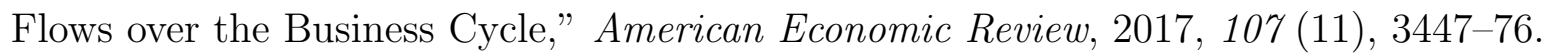

Kudlyak, Marianna and Fabian Lange, "Measuring Heterogeneity in Job Finding Rates among the Non-Employed Using Labor Force Status Histories," 2018. San Francisco Fed WP No. 2017-20.

Menzio, Guido, Irina A. Telyukova, and Ludo Visschers, "Directed search over the life cycle," Review of Economic Dynamics, 2016, 19, 38 - 62.

Morchio, Iacopo, "Work Histories and Lifetime Unemployment," International Economic Review, 2019. Forthcoming.

Mortensen, Dale T. and Christopher Pissarides, "Job Creation and Job Destruction in the Theory of Unemployment," Review of Economic Studies, 1994, 61 (3), 397-415.

Poterba, James M. and Lawrence H. Summers, "Reporting Errors and Labor Market Dynamics," Econometrica, 1986, 54 (6), 1319-1338.

Pries, Michael J., "Persistence of Employment Fluctuations: A Model of Recurring Job Loss," The Review of Economic Studies, 2004, 71 (1), 193-215.

Rust, John, "Structural Estimation of Markov Decision Processes," Handbook of Econometrics, 1994, 4, 3081-3143.

Shibata, Ippei, "Labor Market Dynamics: A Hidden Markov Approach," November 2015. International Monetary Fund. 


\section{Appendixes}

\section{A Details on the Calculation of the Probability of a State Path}

A key idea in the model is that the transition probabilities among states, $\pi_{\theta, s, s^{\prime}}$, are determined by choices made by the individual based on the Bellman values of the type- $\theta$ individual's dynamic program. The driving forces of transitions are the random arrival of new opportunities and of adverse shocks. An employed person chooses whether to continue in the current job, search for a new better job, which may be immediately successful, or may take one or more months, or exit the labor market. A searcher may encounter a new job, or continue searching, or exit the labor market. A person out of the labor market may become a searcher, again with either immediate success or entry to unemployment, or may choose to remain out of the market.

We calculate the probability of a path $\left[U_{1}, \ldots, s_{8}\right]$, starting at, for example, $U$, as follows: Let $\pi_{\theta}$ be the transition matrix over states for type $\theta$, and $P_{\theta}$ be the associated ergodic distribution vector, with elements $P_{\theta, s}$. The probability of a path for type $\theta$ is the product of $P_{\theta, U_{1}}$, the stationary probability of the specified state in month $1, B_{\theta, s}$, the product of the transition probabilities of the three specified transitions, from month 1 to month 2 , month 2 to month 3 , and month 3 to month $4, C_{\theta, s}$, the probability of the transition from a specified activity in month 4 to the specified activity in month 5 via the 8 unspecified activities in the 8 months when a respondent does not provide data, and $D_{\theta, s}$, the product of the specified transition probabilities from month 5 to month 6 , month 6 to month 7 , and month 7 to month 8.

The compound probabilities are:

$$
B_{\theta, s}=\prod_{t=1}^{3} \pi_{\theta, s_{t}, s_{t+1}}
$$

and

$$
C_{\theta, s}=\pi_{\theta, s_{4},:} \pi_{\theta}^{7} \pi_{\theta,:, s_{5}}
$$

where $\pi_{\theta, s_{4}, \text { is }}$ ise row of the transition matrix corresponding to the specified state in month 4 , and $\pi_{\theta,:, s 5}$ is the column of the transition matrix corresponding to the specified state in month 5. $C_{\theta, s}$ is the probability of being in state $s_{5}$ conditional on having been in state $s_{4}$ and not conditional on the intervening activities hidden from the CPS. Finally,

$$
D_{\theta, s}=\prod_{t=5}^{7} \pi_{\theta, s_{t}, s_{t+1}}
$$


Thus

$$
\tilde{M}_{n}=\sum_{\theta} \omega_{\theta} P_{\theta, s_{1}} B_{\theta, n} C_{\theta, n} D_{\theta, n}
$$

\section{B An Informative Prior on the Transition Matrixes of Types 1 and 5}

We believe that high-E type has transition rates near the following:

$$
\left[\begin{array}{llll}
1 & 0 & 0 & 0 \\
1 & 0 & 0 & 0 \\
1 & 0 & 0 & 0 \\
1 & 0 & 0 & 0
\end{array}\right] .
$$

Individuals of high-E type almost all move immediately to state 1, and thus out of the labor market, and stay there - they are definitely not attracted to work. And we believe the transition matrix of type 5 is near the following,

$$
\left[\begin{array}{llll}
0 & 0 & 0 & 1 \\
0 & 0 & 0 & 1 \\
0 & 0 & 0 & 1 \\
0 & 0 & 0 & 1
\end{array}\right],
$$

embodying the belief that individuals of type 5 are strongly attracted to work.

These constitute 8 preferred values of 1 for the estimated transition probabilities for the two types. We denote the corresponding values of the estimates as $\pi_{1}, \ldots, \pi_{8}$. We take the probability density of the prior on support $\bigcup_{i}[0,1]$ to be $\left.\exp \left(-\phi\left(1-\pi_{i}\right)\right)\right)$. In $\operatorname{logs}$, this amounts to penalizing the log-likelihood by subtracting $\phi \sum_{i}\left(1-\pi_{i}\right)$. Note that our other constraints of non-negativity and summing to 1 guarantee that the other transition rates are close to zero but non-negative.

Without imposing any prior belief about high-E type, the likelihood tends to be maximized with a hybrid high-E type that combines substantial probabilities of staying in state 1 with moderate probabilities of circling through other states - a single type combines two of the kinds of behavior found in the data. This combination makes room, so to speak, for more flexibility in matching other aspects of the observed frequency distribution by a type that does double duty. Similarly, the maximization will yield a hybrid type 5. The implications of the hybrid types are close to the same as for the types we find, but the explanation is more convoluted.

When we specify a fairly weak prior, with $\phi=0.01$, the estimated types all-N and all-E stick to their assigned tasks of dealing with the individuals in the data with strong attachments to non-work or work. These results are almost identical to those shown in the 
paper, which impose the condition as a constraint - that is, a fully informative prior. There is a substantial computational payoff to using the constraint rather than a partly informative prior.

\section{How We Gain Information about the Flow Values}

A simple example helps clarify the information that our model yields about the flow values. The basic point is that the distribution of activity paths imposes inequalities on flow valuesthey are set-identified, not point identified.

Consider a setup with two activities, (1) non-work, with Bellman value $N$, and (2) work, with value $E$. The monthly wage is normalized at 1 , so the value units are in months of work. The flow value of non-work is $z$ and a separating worker receives a payment $b$, which could be unemployment compensation, if positive, or a disamenity of unemployment, if negative. The monthly discount rate is $r$ and the separation rate from work is $\delta$. We take these two values as known parameters. We define the mover partition as one in which a non-worker always finds and takes a job. Spells out of work always last one month. The resulting Bellman equations are

$$
N=z+\frac{1}{1+r} E
$$

and

$$
E=1+\frac{1}{1+r}[(1-\delta) E+\delta(N+b)]
$$

We have a system of two equations in four unknowns: the two Bellman values, the flow value of non-work, $z$, and the separation value $b$. We solve for the pairs of Bellman values on a grid of values of $z$ and $b$. We score a pair as compatible with the mover partition if $V \geq X$ and incompatible otherwise.

Table 13 shows the results of the calculations. If the unemployment benefit $b$ is zero (any benefit paid just compensates for the disamenity of unemployment), the value of $z$ cannot exceed 0.98. If $b$ is negative, the bound is tighter; $z$ must be lower, and correspondingly for a positive value of $b$. 


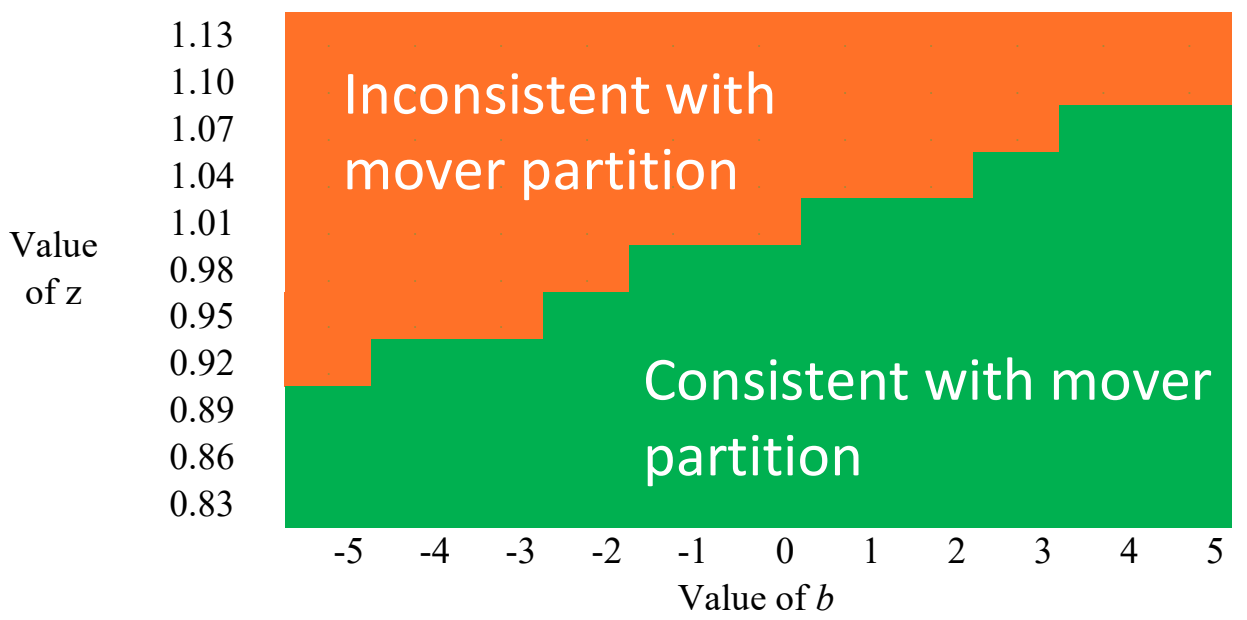

Table 13: Flow Values of Non-Work $z$ and Unemployment Benefits $b$ Compatible with the Mover Partition, in Which the Entire Population Participates in the Labor Market 